\title{
Macroeconomic and Financial Determinants of the Volatility of Corporate Bond Returns
}

Complutense de Análisis Económico

\author{
Belén Nieto \\ University of Alicante
}

Alfonso Novales

University Complutense

Gonzalo Rubio

University CEU Cardenal Herrera

\begin{abstract}
This paper analyzes the relationship between the volatility of corporate bond returns and standard financial and macroeconomic indicators reflecting the state of the economy. We employ the GARCH-MIDAS multiplicative two-component model of volatility that distinguishes the short-term dynamics from the long-run component of volatility. Both the insample and out-of-sample analysis show that recognizing the existence of a stochastic lowfrequency component captured by macroeconomic and financial indicators may improve the fit of the model to actual bond return data, relative to the constant long-run component embedded in a typical GARCH model.
\end{abstract}

Keywords: corporate bonds, volatility, low-frequency component, high-frequency component, macroeconomic indicators, financial indicators

JL Classification G12; C22; E44

\section{Working Paper no 1425}

May, 2014 


\title{
Macroeconomic and Financial Determinants of the Volatility of
}

\section{Corporate Bond Returns}

\author{
Belén Nieto \\ belen.nieto@ua.es \\ University of Alicante, San Vicente del Raspeig, 03690 Alicante, Spain \\ Alfonso Novales \\ anovales@ccee.ucm.es \\ University Complutense, Somosaguas, 28040 Madrid, Spain \\ Gonzalo Rubio \\ gonzalo.rubio@uch.ceu.es \\ University CEU Cardenal Herrera, Elche, 03204 Alicante, Spain
}

This version: May 11, 2014

\begin{abstract}
This paper analyzes the relationship between the volatility of corporate bond returns and standard financial and macroeconomic indicators reflecting the state of the economy. We employ the GARCHMIDAS multiplicative two-component model of volatility that distinguishes the short-term dynamics from the long-run component of volatility. Both the in-sample and out-of-sample analysis show that recognizing the existence of a stochastic low-frequency component captured by macroeconomic and financial indicators may improve the fit of the model to actual bond return data, relative to the constant long-run component embedded in a typical GARCH model.
\end{abstract}

JEL classification: G12; C22; E44

Keywords: corporate bonds, volatility, low-frequency component, high-frequency component, macroeconomic indicators, financial indicators

The authors acknowledge financial support from the Ministry of Science and Innovation through grant ECO2011-29751 (B. Nieto), and the Ministry of Economics and Competitiveness through grants ECO2012-34268 (G. Rubio), and ECO2012-31941 (A. Novales). Financial support from Generalitat Valenciana grant PrometeoII/2013/015 is also acknowledged. We thank Rafael de Rezende, and seminar participants at University of Navarra, University Complutense, and the XXI Finance Forum at IE Business School for helpful comments on the paper. We assume full responsibility for any remaining errors. 


\section{Introduction}

Volatility is the key variable in investment analysis, security pricing, and risk management. It is also the most important variable in option pricing, and it is heavily used in the regulation of financial institutions as the key input to estimate for example, value-at-risk (VaR) measures. Hence, it is not surprising that volatility forecasting and the analysis of the determinants of volatility have become fundamental research issues in financial economics. As opposed to most of the empirical literature, which has focused on the behavior of stock market volatility, we analyze the macroeconomic and financial determinants of corporate bond return volatilities. We use the multiplicative two-component GARCH-MIDAS model of volatility recently proposed by Engle, Ghyselsm and Sohn (2013) and we allow for different characteristics of volatility across six credit rating categories.

Although the typical persistence in stock market volatility is captured by the popular ARCH/GARCH-type models of Engle (1982) and Bollerslev (1986), the dynamics of volatility seems to be better characterized by the component model introduced by Engle and Lee (1999). Their proposal consists of two additive GARCH(1,1) components, one interpreted as a short-run or transitory component, and a second one identified as the long-run or trend component of volatility. ${ }^{1}$ Recently, however, Engle and Rangel (2008) suggest a multiplicative component structure, the Spline-GARCH model, to accommodate non-stationarity features that are captured by the long run volatility component. Volatility is therefore a product of a slowly changing, low-frequency deterministic component picking up the non-stationary characteristic of the process, and a short-run/high frequency part described by a GARCH(1,1) process which means-reverts to one. The deterministic component is supposed to be a function

\footnotetext{
${ }^{1}$ Other relevant papers related to this approach are Chernov, Gallart, Ghysels, and Tauchen (2003), and Adrian and Rosenberg (2008). See Wang and Ghysels (2011) for a review from a statistical perspective.
} 
of macroeconomic variables, and hence volatility ends up being a combination of macroeconomic effects and time series dynamics. Engle and Rangel (2008) apply this model to stock market volatilities across 50 countries and conclude that high volatility is explained by high inflation, slow output growth, high volatility of short-term interest rates, high volatility of production growth, and high inflation volatility.

On top of this, econometric methods involving data sampled at different frequencies have been shown to be useful for forecasting volatility in equity assets as well as to explain the relationship between conditional variance and expected market returns, especially in comparison with the evidence available from the GARCH family. The mixed frequency approach to modeling and predicting volatility known as mixed data sampling (MIDAS hereafter) was introduced in a series of papers by Ghysels, Santa-Clara, and Valkanov (2003, 2005, 2006). The success of MIDAS lies in the additional statistical power that mixed data frequency regressions incorporate from using daily data in estimating conditional variances. In addition, MIDAS allows for a very flexible functional form for the weights to be applied to past squared returns to explain current volatility. ${ }^{2}$

The insight of the MIDAS specification when combining different frequencies motivates Engle, Ghysels, and Sohn (2013) to modify the dynamics of low-frequency volatility methodology employed by Engle and Rangel (2008) under the SplineGARCH model. They suggest interpreting the long-run/low-frequency volatility component in the spirit of MIDAS so that macroeconomic data, sampled at lower frequency, can directly be employed while maintaining the mean reverting unit GARCH

\footnotetext{
${ }^{2}$ González, Nave, and Rubio (2012) also show the relevance of the weighting schemes of MIDAS when estimating conditional covariances as the cross products of portfolio returns and aggregate factor returns in the cross-sectional estimation of the market risk premium.
} 
dynamics for the short-run component. This new class of models is called GARCHMIDAS.

Contrary to the huge number of papers dealing with stock market volatilities, relatively little work has been done to understand corporate bond volatility dynamics. This is surprising. It may have been overlooked because of a possible similarity with equity or currency volatilities or it may have been considered not to be useful in practice. A more likely reason may have been related to the lack of high-frequency transaction data on corporate bonds. ${ }^{3}$ We think that the study of corporate bonds volatility is important for several reasons. First, it should facilitate a more rigorous risk management of corporate bond portfolios or portfolios that combine both equities and corporate bonds as a way of diversifying risks. Second, it may clarify capital structure decisions and, in particular, the market timing decisions of issuing new debt or new equity, as well as the speed of adjustment towards target leverage. Third, it is a necessary first step to analyze the correlation between stock and corporate bond returns at individual level. Finally, it complements the recent and prolific empirical analysis on liquidity.

This paper fills this gap by analyzing the macroeconomic and financial determinants of the volatility of corporate bond returns across six credit rating categories by applying the GARCH-MIDAS specification. This methodology allows us to disentangle the impact of macroeconomic conditions on corporate bond volatility from the short-run dynamics. To the best of our knowledge this is the first paper directly analyzing this issue.

We find that, for most financial or macroeconomic indicators, the in-sample recognition of a low frequency component of volatility in corporate bond returns

\footnotetext{
${ }^{3}$ A similar pattern has been observed with respect to liquidity of corporate bonds. Using the recently available TRACE data Bao, Pang, and Wang (2011) analyzes both the time-series and cross-sectional behavior of corporate bond liquidity.
} 
significantly improves the likelihood of the GARCH specification, relative to a constant long-term component, with independence of the credit rating category. In particular, high volatility is explained by high levels of default premium, VIX, and equity marketwide illiquidity. Similarly, high volatility of corporate bonds is related to slow growth of industrial production, consumption, and employment, high inflation and high volatility of consumption growth. Not surprisingly, we also get evidence that volatility sensitivities to changes in financial or macroeconomic indicators are often monotonic in the rating of corporate bonds. For instance, high levels of default premium, VIX, market-wide illiquidity, and inflation have a much higher impact on CCC than in AAA bonds.

Finally, the out-of-sample analysis confirms the relevance of the GARCH-MIDAS model relative to the constant- $\tau$ volatility specification when explaining corporate bond volatilities. In particular, it is interesting to note the significant impact of aggregate macroeconomic and financial risks on CCC corporate bonds for out-of-sample forecasting.

This paper is organized as follows. Section 2 provides a summary of findings from related papers. Section 3 describes the data employed in the analysis, and Section 4 presents preliminary evidence on corporate bond returns volatility. Section 5 briefly describes the new class of multiplicative component models for asset volatility, and section 6 reports and discusses our in-sample empirical results on the relationship between corporate bond volatility and macroeconomic and financial indicators. Section 7 further motivates the results analyzing the behavior of the model during normal/expansion and recession periods, and Section 8 presents the out-of-sample results. Section 9 concludes. 


\section{Related Literature on Corporate Bond Volatilities}

Regarding the relation between macroeconomic conditions and the behavior of corporate bonds, one of the most demanding issues refers to the credit spread puzzle. Huang and Huang (2003) show that structural default models generate credit spreads much lower than the historical differences between Aaa and Baa corporate bonds. The two papers putting forward a potential solution of this puzzle consider the effects of macroeconomic conditions on corporate bond yields. Chen, Collin-Dufresne, and Goldstein (2009) use the Campbell and Cochrane (1999) model with habit preferences to show that time-varying risk aversion, together with a capital structure mechanism to match the countercyclical nature of defaults, can account for the high corporate bond spreads. In their model, investors are sensitive to the timing of defaults since high yield bond defaults are more likely to occur in recessions, when risk aversion is particularly high. Rather than modeling risk aversion, Chen (2010) employs time-varying consumption risk in the spirit of the long-run model of Bansal and Yaron (2004) to show that heteroskedastic long-run aggregate consumption risk makes firms default more likely in recessions and generates a more disrupting environment for both stock and bond holders. Given the response of firms to macroeconomic conditions, Chen's model endogenously incorporates countercyclical fluctuations in risk prices, default probabilities, and default losses. This simultaneous co-movement generates the large credit spreads that explain not only the credit spread puzzle but also the low-leverage ratios historically reported by firms.

Therefore, macroeconomic conditions have been used to explain the level of credit spreads over time. However, none of these papers address the issue of how macroeconomic conditions affect corporate bonds volatility. Similarly, Rachwalski (2011) shows that corporate bond returns predict consumption growth and labor income 
growth even after controlling for equity returns. Additionally, the covariance between corporate bonds and stock returns predicts the stock market index. But, as the previous authors, Rachwalski (2011) does not discuss the relationship between corporate bond volatility and macroeconomic conditions.

Finally, there are other papers analyzing the cross-sectional variation of corporate bond returns. Fama and French (1993) first show that default and term premia are priced factors in the corporate bond market. Gebhardt, Hvidkjaer, and Swaminathan (2005) show that default betas are significantly related to the cross-sectional variation of average bond returns. Furthermore, yield-to-maturity remains the only significant characteristic after controlling for default and term betas, suggesting that systematic risk factors are important for pricing corporate bonds. Lin, Wang, and Wu (2011) argue that market-wide liquidity risk is also a priced factor in the cross-section of corporate bonds as implied by their finding of a positive and significant relation between average bond returns and liquidity beta which is robust to including default and term betas. Acharya, Amihud, and Bharath (2013) also show that time-varying liquidity risk matters for corporate bonds, suggesting a flight-to-liquidity aspect in the corporate bond market on top of the well-known flight-to-quality. Moreover, as pointed out above, using transaction-level data from 2003 to 2009, Bao, Pang, and Wang (2011) find that marketwide liquidity explains a substantial variation of credit yield spreads, and that illiquidity is also priced in the cross-section of corporate bond returns. Once again, a liquidity factor is used to explain the time series behavior of yield spreads but not the volatility of corporate bonds.

The work more closely related in spirit to our research is Cai and Jiang (2008) who show that, during the 1996-2005 period, corporate bond excess return volatility is directly related to contemporaneous bond excess returns. They also argue that bond 
volatility is a significant predictor of the three-month and six-month future corporate bond excess returns. More importantly, they decompose aggregate bond volatility into market, time-to-maturity, and rating components, to find that corporate bond volatility has both a slow-moving and a high-frequency component. They identify the lowfrequency component with the trend displayed by the rating volatility that shows a positive trend until 2002, followed by a declining pattern until 2005. However, they do not statistically decompose both components and they do not investigate the macroeconomic sources of the slow-moving pattern of volatilities. Moreover, their analysis is performed at the aggregate level rather than investigating the behavior of corporate bond volatilities throughout credit ratings.

\section{The Data}

Our corporate bond volatility study covers the period from January 1997 to January 2012. Daily yields on corporate bonds come from the files of Bank of America / Merrill Lynch for six credit bond rating classes: AAA, AA, A, BBB, BB, and CCC or below. ${ }^{4}$ Figure 1 displays the yields for the last day of each month for all credit ratings. Their evolution over time reflects a relatively parallel behavior, with the expected peaks during financial crises, especially for corporate bonds rated as BB or lower. Yields of CCC corporate bonds tend to be much higher than for other ratings, with an impressive overall high of almost 40\% during November 2008.

Our objective is to understand the behavior of corporate bond volatilities, which implies that we are specifically concerned with percentage changes in corporate bond prices. Given that we need daily corporate bond returns in order to estimate the multiplicative GARCH-MIDAS model, and that transaction prices are only available

\footnotetext{
${ }^{4}$ Hereafter we call "CCC” when referring to the "CCC and below” rating class.
} 
from 2002 onwards, we approximate the variation in prices from the variation in yields as follows,

$$
\log \left(\frac{P_{t+1}}{P_{t}}\right) \cong \log \left(\frac{N /\left(1+y_{t+1}\right)^{T}}{N /\left(1+y_{t}\right)^{T}}\right)=\log \left(\left(\frac{1+y_{t}}{1+y_{t+1}}\right)^{T}\right)
$$

where $P_{t}$ is the price of a corporate bond at time $t, y_{t}$ is the yield, $N$ is the nominal value of the bond, and $T$ is the time to maturity. ${ }^{5}$

Panel A of Table 1 displays descriptive statistics for corporate bond yields in our sample. High yield bonds present very high standard deviations, positive skewness and excess kurtosis relative to high-rated bonds. Additionally, correlation coefficients are high for similar rating classes, and they decrease when we consider the return on bond classes with very different rating. The correlation between AAA and CCC bond returns is as low as 0.35 .

Similarly, Panel B of Table 1 contains information regarding corporate bond returns. Average returns present a decreasing pattern, due to the effect of ignoring coupon payments. However, mean values are not relevant for our study. What is really important is the dispersion in return volatilities. The annualized volatility of CCC bonds is $37.9 \%$, relative to a volatility of $7.6 \%$ for AAA bonds. It must be taken into account that the variability in yields is fully translated to the variability in prices if the bond has fixed coupon. Indeed, the maximum and minimum annualized returns correspond to CCC bonds. In terms of returns, the BBB and BB categories have the highest negative skewness and excess kurtosis, and CCC bonds have more negative skewness and higher excess kurtosis than AAA bonds. The correlation patterns are very similar to the correlations reported for yields. The lowest correlations among all corporate bonds are those between the returns of the AAA/AA categories and the returns of B/CCC bonds.

\footnotetext{
${ }^{5}$ We use the average time-to-maturity of the corporate bonds available in TRACE which is equal to 7.8 years.
} 
Yields-to-maturity for the 3-month Treasury bill, the 10-year government bond and Moody's Baa corporate bond series are obtained from the Federal Reserve Statistical Releases. We then compute two state variables based on these interest rates: a term structure slope (Term), computed as the difference between the 10-year government bond and the Treasury bill rate, and a default premium (Default), calculated as the difference between Moody's yield on Baa corporate bonds and the 10-year government bond yield.

We collect from National Accounts four alternative proxies for macroeconomic growth as well as the price deflator. Monthly data for the industrial production index (IPI) are downloaded from the Federal Reserve, with series identifier G17/IP Major Industry Groups. Seasonally adjusted consumption expenditures and price indexes on nondurable goods and services come from National Income and Product Accounts (NIPA) Tables 2.8.5 and 2.8.4, respectively, available at the Bureau of Economic Analysis. Population data are from NIPA's Table 2.6. This information is used to construct real per capita consumption expenditures on nondurable goods and services and the corresponding inflation rate. Additionally, we also employ aggregate per capita stockholder consumption growth rate computed as in Malloy, Moskowitz, and VissingJorgensen (2011). Exploiting micro-level household consumption data, these authors show that long-run stockholder consumption risk explains the cross-sectional variation in average stock returns better than the aggregate consumption risk obtained from nondurable goods and services. On top of that, they report plausible risk aversion estimates. They employ data from the CEX for the period from March 1982 to November 2004 to extract consumption growth rates for stockholders, the wealthiest third of stockholders, and non-stockholders. In order to extend their available time period, they construct factor-mimicking portfolios by projecting the stockholder 
consumption growth rate on a set of instruments, and use the estimated coefficients to generate a longer time series of instrumented stockholder consumption growth. We employ these reported estimated coefficients for generating a factor-mimicking portfolio with the same set of instruments for stockholder consumption during our sample period. The last macroeconomic indicator is the non-farm employment growth rate which comes from the Bureau of Labor Statistics, "B" tables of the seasonal adjusted employment situation release.

Figure 2 displays aggregate per capita consumption, stockholder consumption, and employment annual growth rates from 1960 to 2011. The time series behaviour of aggregate consumption and employment growth rates is very similar, being smoother than the growth rate of stockholder consumption. However, the troughs and peaks of the three series tend to have the same time location. On the other hand, as expected, these peaks are much more pronounced for stockholder consumption growth than for either aggregate consumption or employment growth.

Daily data on VIX is obtained from the Chicago Board Options Exchange (CBOE) and the last day of each month is used to create a final monthly option-implied volatility series.

We use the Pastor and Stambaugh (2003) measure of market-wide illiquidity, which reflects the amount in which stock returns rebound upon high volume. Their measure is based on daily regressions of individual stock excess returns over the market return in a calendar month,

$$
R_{j, t+1}^{e m}=a+b R_{j, t}+g\left\lfloor\operatorname{sign}\left(R_{j, t}^{e m}\right)\right\rfloor D V o l_{j, t}+e_{j, t+1},
$$

where $R_{j, t+1}^{e m}$ denotes the excess return of stock $j$ over the market return. Pastor and Stambaugh aggregate the estimates of the $g$ coefficient across stocks and scale it for growing dollar volume. They finally propose the innovations in this regression as the 
final measure of illiquidity. ${ }^{6}$ The intuition is that high volume moves prices away equilibrium and they rebound the following day, which suggests that $g$ is typically negative.

Finally, we also employ as indicators two additional proxies of economic risk: the volatility of consumption growth and stockholders consumption growth, estimated as the square residuals from univariate auto-regressive processes of order twelve.

Table 2 contains descriptive statistics for the financial and macroeconomic indicators used throughout this research. Annualized volatility is relatively high for industrial production and stockholder consumption growth, VIX, and especially marketwide illiquidity. VIX is highly and positively correlated with the default premium and negatively correlated with macroeconomic variables, especially stockholder consumption growth, and employment growth. In terms of monthly growth, employment presents a higher correlation with industrial production and aggregate consumption than with stockholder consumption, and the default premium has a negative correlation with industrial production, consumption, and especially with employment growth.

\section{Preliminary Evidence on Conditional Corporate Bonds Volatility}

Given the lack of existing studies on corporate bond volatility, and before comparing the more elaborate GARCH-MIDAS model with the classical GARCH, we study some properties characterizing corporate bond volatilities using the traditional GARCH $(1,1)$ specification and the dynamic conditional correlation (DCC) framework.

\footnotetext{
${ }^{6}$ The monthly series are available in Lubos Pastor's web site.
} 
Figure 3 contains the conditional volatility estimated from a GARCH $(1,1)$ model for three representative credit ratings, i.e., AAA, BBB, and CCC corporate bonds. The behavior displayed by conditional volatilities shows the expected pattern. The conditional volatility of CCC (right axis) is not only systematically above the conditional volatilities of the other two ratings, but also presents larger peaks during crisis periods. Thus, estimated conditional volatilities are dominated by the huge increase after October 2008, as a consequence of the Lehman Brothers crisis. The volatility of CCC bonds rises in the following months to $154 \%$, whereas those for AAA and $\mathrm{BBB}$ bonds (left axis) increase to $14 \%$ and 33\% respectively. Except for the different rise during the crisis, there is no significant difference between the levels of volatilities of AAA and BBB bonds. However, it is important to note that the volatility of volatility is higher for BBB bonds relative to AAA bonds. Indeed, we know that the excess kurtosis of BBB is much higher than the kurtosis of AAA bonds.

The evidence on ARCH structures is clear in all cases from the autocorrelation functions for monthly squared returns. This evidence is displayed in Figures 4.a and 4.b for AAA and CCC bonds, respectively. ${ }^{7}$ A GARCH $(1,1)$ seems to capture the persistence in volatility appropriately, as indicated by the comparison between autocorrelation functions of squared returns and standardized squared returns using the estimated GARCH $(1,1)$ conditional volatility. The usual statistics to test for possible specification errors, such as autocorrelation of standardized squared residuals using the estimated conditional volatilities or Lagrange multiplier tests for ARCH structures, do not detect any obvious misspecification for any rating class.

Given that we are specifically interested on the information content of macroeconomic and financial indicators regarding corporate bond volatility, we

\footnotetext{
${ }^{7}$ The evidence on the persistence of volatility is even more noticeable for daily squared returns, but for the sake of the argument in this section, we just analyze monthly returns.
} 
estimate again the GARCH $(1,1)$ model adding either an economic or a financial state variable as an explanatory volatility factor. Table 3 reports the results using our set of indicators and corporate bond returns for the two extreme rating categories, namely AAA and CCC bonds. Once again, the empirical evidence shows reasonable economic results. For both AAA and CCC bond returns, higher growth rates of consumption, stockholder consumption, and employment reduce their volatility and higher market equity volatility (VIX), market-wide illiquidity, and consumption volatility significantly increases their volatility. Additionally, industrial production growth is also negatively related to the volatility of AAA bond returns while the risk of default significantly affects the volatility of the bonds returns in the highest risk class.

Finally, Figure 5 displays the estimated dynamic conditional correlations between pairs of $\mathrm{AAA}, \mathrm{BBB}$, and $\mathrm{CCC}$ bond returns, suggesting some differences in their determinants or in their reactions to shocks in them. The estimated correlation between AAA and CCC bonds is positive but relatively small. The low values of this correlation suggest that while AAA and CCC bond returns tend to respond to a given change in their common determinants by moving in the same direction, its overall impact is relatively small. The conditional correlation between BBB and CCC bond returns is indicative of a more similar reaction to common determinants. AAA and BBB bond returns seem to experience similar reactions, with a high and positive conditional correlation over the whole sample. The three conditional correlations experience a sharp increase in October 2008, reflecting the fact that the increased risk perception produced by the fall of Lehman Brothers initially led to a downturn in returns for most assets. The correlations of both AAA and BBB bond returns with CCC returns initiated a gradual comeback to their long-run average that still continued at the end of our sample. Interestingly, AAA and BBB returns experience a decoupling process after the October 
2008 peak, with their correlation falling well below its long-run average. That might be a reflection of the fact that over the last four months of 2008, CCC and BBB bonds lost $77 \%$ and $19 \%$ of their value, respectively, while AAA bonds decreased by only $2 \%$. A simple exercise that assumes an investment of $\$ 1.00$ at the beginning of our sample period shows that, by the end of our sample in January 2012, CCC bond prices still were at $30 \%$ of their initial value. Gains from investments in AAA and BBB bonds would have also been lost by the summer of 2008. Since then, AAA and BBB bonds yielded a $35 \%$ and $16 \%$ return, respectively, in the three years before the end of the sample.

The different levels and dynamics of correlation between pairs of bonds in different risk classes show the different nature of their returns and justify a formal and more rigorous analysis of their volatility.

\section{The Multiplicative GARCH-MIDAS Two-Component Model of Volatility}

The essence of the MIDAS approach is to consider data with different sampling frequency. In our case, we combine daily data for the returns of corporate bonds across different credit ratings with monthly data for the macroeconomic and financial indicators.

Let $r_{i, t}$ be the return on a bond on day $i$ of month $t$, and $N_{t}$ is the number of business days within this month. We assume that daily returns follow a statistical structure given by

$$
r_{i, t}=\mu+\eta_{i, t},
$$

where $\eta_{i, t}$ is an innovation normally distributed with zero mean and conditional variance $\sigma_{i, t}^{2}=\tau_{t} g_{i, t}$, where $g_{i, t}$ is the high-frequency component following a unit 
$\operatorname{GARCH}(1,1)$ process, and $\tau_{t}$ is the stochastic low-frequency component. ${ }^{8}$ Thus, the return can be written as

$$
r_{i, t}=\mu+\sqrt{\tau_{t} g_{i, t}} \varepsilon_{i, t}
$$

where $\varepsilon_{i, t}$ is a shock with distribution $\mathrm{N}(0,1)$ given the information available up to day (i-1) of month $t$.

As in Engle, Ghysels, and Sohn (2013), we assume that the volatility dynamics of the component $g_{i, t}$ is a daily $\operatorname{GARCH}(1,1)$ process given by

$$
g_{i, t}=(1-\alpha-\beta)+\alpha \frac{\left(r_{i-1, t}-\mu\right)^{2}}{\tau_{t}}+\beta g_{i-1, t}
$$

where $\alpha+\beta<1$.

On the other hand, the low-frequency (monthly) component $\tau_{t}$ is assumed to respond to economic conditions over a relatively long period of time where these conditions are represented by either macroeconomic or financial indicators. Thus, in the spirit of MIDAS regression and filtering, the $\tau_{t}$ component is assumed to be a smoothed measure of past values of some driving variable. ${ }^{9}$

$$
\log \tau_{t}=m_{l}+\theta_{l} \sum_{k=1}^{K_{l}} \phi_{k}\left(\omega_{1, l}, \omega_{2, l}\right) X_{t-k}
$$

In our case, $X$ denotes either the level or the variance of a macroeconomic or financial indicator. In this specification, the low-frequency component $\log \left(\tau_{t}\right)$ varies from month

\footnotetext{
8 Note that in the original two-component model of Engel and Rangel (2008) the low frequency component is deterministic, while in this specification $\tau_{t}$ is stochastic. This is the modification suggested by Engle, Ghysels and Sohn (2013).

${ }^{9}$ In the usual MIDAS approach, the low-frequency component is a smoothed measure of the realized variance of the asset itself. This can be easily introduced in the specification above. However, in this research, we will focus on the impact that either macroeconomic or financial indicators have on the future variance of asset returns.
} 
to month but it stays the same for all days in a given month. This is the GARCHMIDAS model with fixed time span indicator. ${ }^{10}$

As in Engle, Ghysels, and Sohn (2013), we assume the expectation of the highfrequency component to be equal to its unconditional expectation $\left(E_{t-1}\left(g_{i, t}\right)=1\right)$ at the beginning of the period. Therefore, the long-run component is given by,

$$
E_{t-1}\left[\left(r_{i, t}-\mu\right)^{2}\right]=\tau_{t} E_{t-1}\left(g_{i, t}\right)=\tau_{t} \text {. }
$$

Finally, we assume a beta weighting scheme for equation (6), given by

$$
\phi_{k}\left(\omega_{1}, \omega_{2}\right)=\frac{\left(\frac{k}{K}\right)^{\omega_{1}-1}\left(1-\frac{k}{K}\right)^{\omega_{2}-1}}{\sum_{k=1}^{K} \phi\left(\omega_{1}, \omega_{2}\right)}
$$

As discussed by Ghysels, Sinko, and Valkanov (2006), this beta-specification is very flexible, being able to accommodate increasing, decreasing or hump-shaped weighting schemes.

The model can be estimated using log-likelihood techniques. For each credit rating and for each financial or macroeconomic indicator, using either level or volatility values, we estimate the set of parameters $\Theta=\left(\mu, \alpha, \beta, m, \theta, \omega_{1}, \omega_{2}\right)$ by maximizing the following log-likelihood,

$$
\begin{aligned}
\log L\left(\left\{r_{i, t}\right\}_{i=1,2, \ldots, N_{t}}^{t=1,2, \ldots, T}\right)= & \sum_{t=1}^{T} \sum_{i=1}^{N_{t}} \log \left[\frac{1}{\sqrt{2 \pi \tau_{t} g_{i, t}}} e^{-\frac{\left(r_{i, t}-\mu\right)^{2}}{2 \tau_{t} g_{i, t}}}\right] \\
& =-\frac{1}{2} \sum_{t=1}^{T} \sum_{i=1}^{N_{t}}\left(\log 2 \pi+\log \left(\tau_{t} g_{i, t}\right)+\frac{1}{2} \frac{\left(r_{i, t}-\mu\right)^{2}}{\tau_{t} g_{i, t}}\right)^{.}
\end{aligned}
$$

\footnotetext{
${ }^{10}$ It can be easily extended to allow for a rolling window structure, which we do not pursue in this paper.
} 


\section{In-Sample Estimates of GARCH-MIDAS Model of Corporate Bond Volatilities with Financial and Macroeconomic Indicators}

Next, we estimate the GARCH-MIDAS model given by expressions (4), (5), and (6) where the weights applied to past values of the indicators are given by the betaweighting scheme in (8). For each credit rating and each financial or macroeconomic indicator we maximize the log-likelihood function given by (9). The number of lags in the long-run component, $K$, is different for each corporate bond and indicator, and in all cases, we employ the lag that maximizes the log-likelihood function. The estimation combines the daily return data for corporate bonds with the monthly data for the financial and macroeconomic indicators.

The empirical results are reported in Table 4.a through Table 4.k, where each table corresponds to a particular financial or macroeconomic state variable and contains the results for all credit rating categories. We report the estimated parameters given by the set $\Theta=\left(\mu, \alpha, \beta, m, \theta, \omega_{1}, \omega_{2}\right)$ with the standard errors in parentheses, the value of the log-likelihood function, and the likelihood ratio obtained by comparing the estimated model with the nested benchmark model given by the specification with constant longrun component. In brackets, below the likelihood ratio statistic, we report its $p$-value. ${ }^{11}$

In all cases, the $\alpha$ and $\beta$ parameters of the short-run component given by the unit GARCH process are estimated with precision and present reasonable and similar values across all state variable indicators. In general for all rating classes, the estimated mean for the short-run dynamics is close to zero, as expected in daily return data. The average estimated alpha (beta) for the AAA bond is slightly higher (lower) than for the CCC bond, and the persistence, measured as the sum of both parameters, is also slightly

\footnotetext{
${ }^{11}$ We recognize that a potentially serious issue of fitting the model many times separately is multiplicity. The significance of results for some indicators in some scenarios might just be because of chance, even though they might not be significant. Therefore, interpretation of our results must be made with caution. In any case, the out-of-sample exercise we report later in the paper alleviates this issue.
} 
higher for the CCC bond. The exception is the B rated bond for default premium, term premium, illiquidity, and consumption volatility, for which we estimate a higher alpha relative to other bonds and indicators.

Estimated weights tend to vary across cases presenting different shapes ranging from monotonically decreasing to hump-shaped weights, and the lag attaining the maximum value also varies across ratings and state variable indicators. It is also the case that the weight parameters tend to be estimated with low precision. Given that we take logs to estimate the long-run component, the mean of the long-run component, $m$, is negative by construction and it is estimated with precision in all cases.

We are particularly interested in the slope parameter of the long-run component, $\theta$. It indicates whether the past behavior of a financial or macroeconomic indicator anticipates either an increase or a decrease in the volatility of corporate bond returns. It turns out that, independently of the corporate bond rating, $\theta$ is strongly significant for most indicators. Moreover, the long-run component coefficient is significant for bonds in the extreme risk class for all state variables employed in estimation. This suggests that the recognition of the long-run component is a key factor for a better understanding of the behavior of the volatility of corporate bond returns. The $\theta$ estimates tend to have the expected sign. They are positive when an increase in the state variable implies a negative shock for the economy, and negative for those cases in which an increase represents a positive shock. Overall, we find that increasing values of the default premium, VIX, illiquidity, inflation, and consumption volatility anticipate higher future volatility of corporate bond returns, while increasing values of production, consumption, or employment growth as well as the term premium, anticipate lower volatility in corporate bond returns. Moreover, although the sign is exactly what we 
expected, the relative impact of the indicator on the long run component of the bond volatility is quite different across credit rating categories.

In order to appreciate this point, Figure 6.A and Figure 6.B display the $\theta$ estimates for state variable indicators that generate more and less volatility respectively across credit rating categories. For a better comparison, $\theta$ is divided by its crosssectional standard deviation across credit ratings. Analyzing bad-news indicators, VIX seems to be the most relevant factor explaining corporate bond returns volatilities for all credit ratings, although the impact of VIX is especially large for the $\mathrm{BB}, \mathrm{B}$, and CCC categories. Similarly, the default premium presents an increasing impact when we move from AAA to CCC bonds. Together with VIX, they become the key factors generating the trend of return volatility for CCC bonds. Consumption volatility also has a similar, although smoother, increasing pattern across ratings, but it becomes less relevant for CCC bonds. On the other hand, stockholder consumption volatility seems to have a higher impact on the AAA category. ${ }^{12}$ Finally, inflation, and market-wide illiquidity become more important the lower is the credit rating class. ${ }^{13}$ Hence, in terms of CCC bonds, VIX, the default premium, inflation, and illiquidity shocks are the most relevant indicators of bond return volatility, while VIX and stockholder consumption volatility dominate the volatility of AAA bonds. On the good-news side, industrial production growth is practically the most relevant factor anticipating a reduction in corporate bond volatility for all rating classes. Consumption and employment growth are also macroeconomic state variables explaining a long-run reduction in volatility. It is interesting to point out that these macroeconomic indicators seem to have more impact

\footnotetext{
${ }^{12}$ This is an intriguing result that deserves more attention. It may easily be the case that stockholder consumption is a relevant state variable not only for equities but also for corporate bonds as long as they are the less risky bonds financing the companies.

${ }^{13}$ It is well known that inflation is one of the key variables explaining discount factors for government bonds. Higher expected inflation makes future money less appealing, so discount rates decrease. This effect seems to be especially relevant the higher the risk of the bond. The effect of inflation risk expands with the risk of corporate bonds.
} 
on the $\mathrm{BB}$ and $\mathrm{B}$ categories than on CCC bonds. Indeed, the effects of production, consumption, and employment growth on the volatility of AAA and CCC are quite similar, but less than for the BB and B bonds.

Finally, we must test the in-sample overall statistical significance of the model specification that incorporate a stochastic behavior for the long-run component of volatility relative to the specification in which the low-frequency component is assumed to be constant. Hence, the benchmark model is the GARCH-MIDAS model with constant $\tau$. The last column of Tables 4.a to 4.k provides the likelihood ratio test statistic and the corresponding $p$-value. Out of the 77 cases analyzed (11 state variable indicators by 7 credit rating categories), in 54 cases the test indicates a statistically significant improvement in fitting the data when incorporating the stochastic long-term volatility component. It also implies that a number of macroeconomic and financial indicators contain relevant information concerning future conditional volatility of corporate bond returns. Moreover, for some of the most relevant indicators, i.e. VIX, industrial production, and consumption and employment growth, we always reject the constant $\tau$ specification. The default premium, inflation, market-wide illiquidity, stockholders' consumption growth and aggregate consumption volatility contain explanatory power on future volatility of bond returns for the lower rating classes (BB and below). The volatility of stockholder consumption seems to contain information on future volatility for high credit rating bonds.

\section{Interpreting the Role of Economic Indicators in In-Sample Volatility Estimation}

Since we have just shown that there is ample evidence of information content in macroeconomic and financial indicators on future bond returns volatility for all bond classes, the next step is to try to advance some intuition on this evidence. To that end, 
we split the sample between recession and normal/expansion periods to examine the different behavior of AAA and CCC bond return volatility in each sub-sample. The approach we follow is that having shown a generally better likelihood fit for the GARCH-MIDAS model, we take any significant departure from its implied volatility relative to the constant- $\tau$ volatility as an improvement in volatility estimation.

Figures $7 \mathrm{a}$ and $7 . \mathrm{b}$ show the differences between volatility estimates from the GARCH-MIDAS approach using macroeconomic indicators and the constant- $\tau$ approach for the AAA and CCC bonds respectively. Regarding high credit quality bonds, and for most of the sample period, the GARCH-MIDAS method with macroeconomic indicators generates higher volatility than the constant $\tau$-approach. These differences sharply decline over the first half of the recent recession period. In fact, from October of 2008 until the official end of the crisis, the model specification without macroeconomic indicators generates higher volatility. It seems that the recognition of macroeconomic indicators during crisis smoothes volatility of AAA bonds relative to the constant $\tau$-approach. On the other hand, for CCC bonds, the difference keeps changing from positive to negative depending upon the economic situation. The differences become much larger during recessions, and they become positive at the end of recessions and the beginning of expansions when the volatility of the GARCH-MIDAS model is higher than the volatility generated under the constant $\tau$ approach.

Figures 8.a and 8.b contain the differences in volatilities for key selected financial indicators as VIX and default premium. For AAA bonds, the GARCH-MIDAS model seems to generate less volatility for both indicators during recession periods, but for CCC bonds, this is only the case for VIX. 
To examine whether this graphical evidence leads to statistically significant conclusions on the comparison between the characteristics of the time series of volatility estimated from both modeling strategies, we use a simple regression approach:

$$
\hat{\sigma}_{t}^{G M}-\hat{\sigma}_{t}^{C n t}=\alpha+\beta \times \operatorname{EXPANSION}_{t}+u_{t},
$$

where $\hat{\sigma}_{t}^{G M}$ is the volatility generated by the GARCH-MIDAS model, $\hat{\sigma}_{t}^{C n t}$ is the volatility obtained under the constant- $\tau$ specification, and EXPANSION is a dummy variable that takes the value of 1 whenever month $t$ does not belong to the NBER official recession dates, and zero otherwise. This implies that the intercept $\alpha$ is the average difference between the volatilities generated by both models over recessions, while the slope $\beta$ indicates how the difference in estimated volatilities changes in normal/expansions times, relative to recession periods. The sum $\alpha+\beta$ is the average difference of volatilities over normal/expansion times.

For both AAA and CCC corporate bonds, Table 5 contains estimates of the intercept and the slope in each regression, as well as the $p$-values for the significance tests, obtained using standard errors robust to the presence of heteroskedasticity and autocorrelation. In the interpretation that follows we will focus on coefficients estimated with a $p$-value below 0.10 .

Coefficient estimates are consistent with our previous comments on the time behavior of volatility from both types of models over recession and expansion times. For AAA bonds, we obtain a positive intercept for most of the macroeconomic indicators, reflecting the observation that the GARCH-MIDAS volatility is, on average, higher in recession periods than the constant- $\tau$ volatility estimate. This is the case despite the sharp decline of the difference between both volatility estimates during the last part of the recent financial crisis, as reflected in Figure 7.a. On top of this, the differences between normal/expansion periods and recessions are positive, as also 
displayed in Figure 7.a, and statistically significant. For key financial indicators, as the default premium and VIX, the intercept is negative and significantly different from zero, meaning that average GARCH-MIDAS volatility is in this case lower than the constant$\tau$ volatility. In normal/expansion times the volatility estimated with the default premium and VIX is significantly higher than the constant- $\tau$ volatility. Hence, during recessions, and for AAA bonds, decreasing (increasing) values of macroeconomic (financial) indicators make the GARCH-MIDAS generated corporate bond volatilities to be higher (lower) on average than the constant- $\tau$ volatility. Relative to macroeconomic indicators, bad news captured by financial indicators during recessions generate short-term noise that make the volatility from the pure GARCH specification to be higher than the volatility from MIDAS-GARCH model. This behavior is displayed in Figure 8.a for the default premium and VIX. Similarly, during normal/expansion times, increasing (decreasing) value of macroeconomic (financial) variables always increase the GARCH-MIDAS volatility relative to the constant- $\tau$ volatility. Thus, we may conclude that the recognition of state variables in the behavior of AAA bonds have a significant impact both during recessions and normal/expansion periods.

For CCC bonds, volatility estimates from the GARCH-MIDAS approach are, on average, lower in recessions than the constant- $\tau$ volatility estimate, leading to negative intercept estimates. Slope estimates have in all cases the opposite sign to the corresponding intercept, leading to a much less consistent difference between the volatility estimates from both modeling approaches in normal/expansion times across indicators. Important exceptions are VIX, and the volatility of both measures of consumption, where the GARCH-MIDAS model generates more volatility during normal/expansion times than the constant- $\tau$ volatility specification. Hence, our estimates suggest that the use of indicators to estimate volatility is of interest for AAA bonds in 
any conditions, whereas in the case of CCC bonds, it is mostly interesting around recession periods.

\section{Out-of-Sample Predictions of the GARCH-MIDAS Model with Financial and Macroeconomic Indicators Relative to the Constant- $\tau$ Volatility Specification.}

The in-sample analysis suggests that the GARCH-MIDAS model with a state variable in the secular component of volatility helps explaining the behaviour of future volatility of corporate bonds, and for some indicators this is true independently of the credit rating category. However, the in-sample analysis and the likelihood ratio test may favour more complicated models due to over-fitting and large sample size. The out-of-sample prediction is relevant when comparing models with different complexity and it might help to reinforce the results reported previously. Because of the high correlations between some of state variables and also to avoid over-parameterization, it should be noticed that state indicators have been included one at a time in the low-frequency component. We now propose an out-of-sample exercise to compare the potential improvement in the forecasting ability of corporate bond volatilities for each indicator.

The out-of-sample test divides the full sample in two subsamples: the estimation period, with $T_{1}$ days, and the forecasting period, with $T_{2}=T-T_{1}$ days. In the first subsample, we estimate the parameters of the constant- $\tau$ GARCH volatility (model 1) and the GARCH-MIDAS specification for each indicator (model 2). Then, with these estimated parameters, we generate the bond returns implied by each model for each of the $T_{2}$ days in the second subsample, and compute their daily standard deviation using a rolling window of 21 past daily returns. This standard deviation will then be compared with the standard deviation computed from realized bond returns in order to measure the forecasting errors. 
More specifically, we divide the entire sample in two sub-periods with approximately the same number of observations; the estimation period employs information regarding each day between January 1997 and August 2004, and the forecasting period includes each day between September 2004 and January 2012. Using the parameters estimated in the estimation period, and for each day in the forecasting period, returns implied by the traditional constant- $\tau$ model (model 1 ) are obtained as

$$
\begin{gathered}
\hat{\tau}_{t}=\hat{m} \\
\hat{g}_{i, t}=(1-\hat{\alpha}-\hat{\beta})+\hat{\alpha} \frac{\left(\hat{r}_{i-1, t}-\hat{\mu}\right)^{2}}{\hat{\tau}_{t}}+\hat{\beta} \hat{g}_{i-1, t} \\
\hat{r}_{i, t}=\hat{\mu}+\sqrt{\hat{\tau}_{t} \hat{g}_{i, t}} \varepsilon_{i, t},
\end{gathered}
$$

where $\varepsilon_{i, t}$ is a standard Gaussian variable with $T_{2}$ realizations. The series for the return volatility is computed as

$$
\hat{\sigma}_{i, t}^{C n t}=S D\left(\hat{r}_{i-21, t}, \ldots, \hat{r}_{i t}\right) \sqrt{12}
$$

Similarly, returns implied by the GARCH-MIDAS model (model 2) for each indicator, and their volatility are obtained as

$$
\begin{gathered}
\hat{\tau}_{t}=\hat{m}+\hat{\theta} \sum_{k=1}^{K} \varphi_{k}\left(\hat{\omega}_{1}, \hat{\omega}_{2}\right) X_{t-k} \\
\hat{g}_{i, t}=(1-\hat{\alpha}-\hat{\beta})+\hat{\alpha} \frac{\left(\hat{r}_{i-1, t}-\hat{\mu}\right)^{2}}{\hat{\tau}_{t}}+\hat{\beta} \hat{g}_{i-1, t} \\
\hat{r}_{i, t}=\hat{\mu}+\sqrt{\hat{\tau}_{t} \hat{g}_{i, t}} \varepsilon_{i, t} \\
\hat{\sigma}_{i, t}^{G M}=S D\left(\hat{r}_{i-21, t}, \ldots, \hat{r}_{i t}\right) \sqrt{12},
\end{gathered}
$$

where the random shock, $\varepsilon_{i, t}$, is the same as in model 1 .

The mean squared error (MSE) for each model is defined as 


$$
\begin{gathered}
M S E_{1}=\frac{1}{T_{2}-21} \sum_{t}^{T_{2}-21}\left(\sigma_{i, t}^{\text {Re } a l}-\hat{\sigma}_{i, t}^{\text {Cnt }}\right)^{2} \\
M S E_{2}=\frac{1}{T_{2}-21} \sum_{t}^{T_{2}-21}\left(\sigma_{i, t}^{\text {Re } a l}-\hat{\sigma}_{i, t}^{G M}\right)^{2},
\end{gathered}
$$

where $\sigma_{i, t}^{\text {Real }}=S D\left(r_{i-21, t}, \ldots, r_{i, t}\right) \sqrt{12}$, and $r_{i, t}$ are realized bond returns.

Finally, the MSE from the two models are compared through the statistic: ${ }^{14}$

$$
F=\left(T_{2}-21\right) \frac{M S E_{1}-M S E_{2}}{M S E_{2}} .
$$

A positive value for the $F$ statistic indicates that the volatility mean squared forecasting error is lower for the GARCH-MIDAS specification with a state indicator modeling the secular volatility component than for the constant- $\tau$ GARCH specification. The same intuitive argument applies for a comparison across different indicators.

Panels A and B of Table 6 contain the out-of-sample results for each financial or macroeconomic indicator for the AAA and CCC corporate bonds, respectively. First row provides the $F$ values from expression (14). Starting with AAA bonds, only three state variables seem to improve the forecasting ability of the GARCH-MIDAS model relative to the constant- $\tau$ volatility specification: The term structure slope, consumption growth, and VIX, where the statistic is especially large for consumption growth and VIX. Results for the other state variables indicate that the standard GARCH specification produces lower forecasting errors than the GARCH-MIDAS model. On the other hand, the results for the CCC rated bonds are completely different. All indicators, with the exception of inflation, reduce the forecasting errors with relation to the constant- $\tau$ model. Now, $F$ values are much higher than for the AAA case, and the

\footnotetext{
${ }^{14}$ See McCraken (2007) for a formal discussion about this statistic.
} 
cases of the default premium, VIX and the volatility of stockholders consumption are especially remarkable. $^{15}$

In order to analyze the dependence of the results to the specific simulated values for the shock $\varepsilon_{i, t}$, we repeat the exercise for 100 different simulations. The second row in Table 6 provides the mean of the 100 values for the $F$ statistic, the third row provides the number of cases in which $F>0$ within the 100 simulations, and Figures 9.a and 9.b plot the 100 values for the MSE from model 1 (constant- $\tau$ GARCH) and form model 2 with some selected indicators. Results in the second and third rows of Table 6 confirm previous conclusions. In the case of AAA bonds, 97 and 94 times out of 100, the use of consumption growth or VIX in the specification of the secular component of the bond volatility substantially improves the prediction. Moreover, in 92 out of 100 cases the use of the term structure slope also reduces the MSE, although the statistic suggests a much lower improvement relative to VIX or consumption growth. For other indicators, such as IPI or aggregate illiquidity, the more complex GARCH-MIDAS specification makes worse the volatility prediction. These results are illustrated in Figure 9.a. On the other hand, the volatility of CCC rated bonds is clearly better predicted by using the default premium, employment growth, VIX or the volatility of consumption growth as indicators for its long-run component. Such large improvement is illustrated in Figure 9.b.

\footnotetext{
${ }^{15}$ It must be noted that the loss differences in expression (14) are measured with error. This implies that the exact distribution of the statistic is also unknown and the asymptotic distribution can only be obtained under restrictive assumptions that include non-nested models. For the case of nested models, Clark and McCracken (2012) suggest deriving the asymptotic distribution by a fixed regressor bootstrap and show that the test statistic based on the proposal bootstrap has good size properties and reasonable finite-sample power. Unfortunately, the framework in which the $F$-statistic and the corresponding statistical inference are developed by McCraken (2007) and Clark and McCraken (2012) do not correspond to our framework. For this reason we do not provide the $p$-values estimated under the $F$-statistic given by (14).
} 


\section{Conclusions}

It is surprising how little we know about the time series behaviour of the volatility of corporate bond returns and about the cross-sectional differences in volatility across credit ratings. This paper studies the explanatory power of macroeconomic and financial indicators on the volatility of corporate bonds for seven credit rating categories using a GARCH-MIDAS approach to separate the short-run and long-run sources of corporate bond volatility. A likelihood ratio in-sample test suggests that, for most indicators, recognizing the secular component of volatility helps explaining the behaviour of future volatility of corporate bonds independently of the credit rating category. More specifically, out of the 77 possible cases analyzed (across 11 indicators and 7 credit ratings), in 54 cases the likelihood ratio test suggests a statistically significant improvement in fitting the data when incorporating the stochastic long-term volatility component. For VIX, the term structure slope, and industrial production, consumption, and employment growth we always reject the constant- $\tau$ volatility specification. The default premium is also a very important financial indicator but its influence is particularly concentrated on low-credit rating categories like BB, B, and CCC corporate bonds.

Paying attention to the extreme rating classes, we obtain that VIX, the default premium, inflation, and illiquidity shocks are the most relevant indicators of bond return volatility for CCC bonds, while VIX and stockholder consumption volatility dominate the volatility of AAA bonds. On the good-news side, industrial production growth is practically the most relevant factor anticipating a reduction in corporate bond volatility for all rating classes. 
A detailed analysis over the sample period suggests that the use of indicators to estimate volatility is of interest for AAA bonds in any conditions, whereas in the case of CCC bonds, it is mostly interesting around recession periods.

Finally, the out-of-sample analysis shows signs of improvement of the GARCHMIDAS model relative to the constant- $\tau$ volatility specification. In the case of AAA bonds this result holds for the term structure slope, consumption growth, and VIX. However, the recognition of the long-run component is especially relevant for forecasting volatility of junk-bonds, where most macroeconomic and financial indicators improve the forecasting ability of the model. It is interesting to note the relevance of aggregate macroeconomic and financial risks when estimating the volatility of CCC corporate bonds. 


\section{References}

Acharya, V., Y. Amihud, and S. Bharath, 2013. Liquidity risk of corporate bond returns: Forthcoming in the Journal of Financial Economics.

Adrian, T., and J. Rosenberg, 2008. Stock returns and volatility: Pricing the short-run and long-run components of market risk. Journal of Finance 63, 2997-3030.

Bansal, R. and A. Yaron, 2004. Risks for the long run: A potential resolution of asset pricing puzzles. Journal of Finance 59, 1481-1509.

Bao, J., J. Pang, and J. Wang, 2011. The illiquidity of corporate bonds. Journal of Finance 66, 911-946.

Bollerslev, T., 1986. Generalized autoregressive conditional heteroskedasticity. Journal of Econometrics 31, 307-326.

Cai, N., and X. Jiang, 2008. Corporate bond returns and volatility. The Financial Review 43, 1-26.

Campbell, J., and J. Cochrane, 1999. By force of habit: A consumption-based explanation of aggregate stock market behaviour. Journal of Political Economy 107, 205-251.

Chen, H., 2010. Macroeconomic conditions and the puzzles of credit spreads and capital structure. Journal of Finance 65, 2171-2212.

Chen, L., P. Collin-Dufresne, and R. Goldstein, 2009. On the relation between the credit spread puzzle and the equity premium puzzle. Review of Financial Studies 22, 3367-3409.

Chernov, M., R. Gallant, E. Ghysels, and G. Tauchen, 2003. Alternative models for stock price dynamics. Journal of Econometrics 116, 225-257.

Clark, T., and M. McCraken, 2012. Reality checks and Nested Forecast Model Comparison. Journal of Business and Economic Statistics 30, 53-66. 
Engle, R., 1982. Autoregressive conditional heteroskedasticity with estimates of the variance of U.K. inflation. Econometrica 50, 987-1008.

Engle, R., and G. Lee, 1999. A permanent and transitory component model of stock return volatility. R. Engle and H. White (editors), Cointegration, causality, and forecasting: A festschrift in honour of Clive W. J. Granger, Oxford University Press 475-497.

Engle, R., and J. Rangel, 2008. The spline GARCH model for low frequency volatility and its global macroeconomic causes. Review of Financial Studies 21, 1187-1222.

Engle, R., E. Ghysels, and B. Sohn, 2013. Stock market volatility and macroeconomic fundamentals. Review of Economics and Statistics 95, 776-797.

Fama, E., and K. French, 1993. Common risk factors in the returns of stocks and bonds. Journal Financial Economics 33, 3-56.

Gebhardt, W., R. Hvidkjaer, and S. Swaminathan 2005. The cross-section of expected corporate bond returns: Betas or characteristics? Journal of Financial Economics 75, 84-114.

Ghysels, E., P. Santa-Clara, and R. Valkanov, 2003. The MIDAS touch. Mixed data sampling regression models. Working Paper, University of California, Los Angeles, and University of North Carolina at Chapel Hill.

Ghysels, E., P. Santa-Clara, and R. Valkanov, 2005. There is a risk-return trade-off after all. Journal of Financial Economics 76, 509-548.

Ghysels, E., P. Santa-Clara, and R. Valkanov, 2006. Predicting volatility: Getting the most out of return data sampled at different frequencies. Journal of Econometrics 131, 59-95.

Ghysels, E., A. Sinko, and R. Valkanov, 2006. MIDAS regressions: Further results and new directions. Econometric Reviews 26, 53-90. 
González, M., J. Nave, and G. Rubio, 2012. The cross-section of expected returns with MIDAS betas. Journal of Financial and Quantitative Analysis 47, 115-135.

Huang, J. and M. Huang, 2003. How much of the corporate-treasury yield spread is due to credit risk? Working Paper, Stanford University.

Lin, H., J. Wang, and C. Wu, 2011. Liquidity risk and expected corporate bond returns. Journal of Financial Economics 99, 628-650.

McCracken, M. (2007) Asymptotics for out-of-sample tests of Granger causality, Journal of Econometrics 140, 719-752.

Malloy, C., T. Moskowitz, and A. Vissing-Jorgensen, 2011. Long-run stockholder consumption risk and asset returns. Journal of Finance 64, 2427-2479.

Pastor, L. and R. Stambaugh, 2003. Liquidity risk and expected stock returns. Journal of Political Economy 111, 642-685.

Rachwalski, M., 2011. Corporate bonds, aggregate wealth, and stock market risk. Working Paper, Emory University.

Wang, F., and E. Ghysels, 2011. Econometric analysis for volatility component models. Working Paper, University of Illinois at Chicago, and University of North Carolina at Chapel Hill. 
Table 1. Corporate bond characteristics by credit rating

\begin{tabular}{|c|c|c|c|c|c|c|c|}
\hline \multicolumn{8}{|c|}{ PANEL A: Annualized Yields to Maturity } \\
\hline & AAA & AA & A & BBB & BB & $\mathrm{B}$ & CCC \\
\hline Mean & 5.01 & 5.13 & 5.64 & 6.38 & 8.08 & 10.01 & 16.33 \\
\hline Volatility & 4.70 & 4.74 & 4.48 & 4.45 & 6.03 & 8.87 & 21.15 \\
\hline Skewness & -0.25 & -0.03 & 0.15 & 0.43 & 1.52 & 1.25 & 1.13 \\
\hline Exc. Kurtosis & -0.54 & -0.99 & -0.69 & -0.12 & 3.92 & 1.94 & 0.64 \\
\hline Max & 7.57 & 7.84 & 9.38 & 10.23 & 15.99 & 20.58 & 38.34 \\
\hline Min & 1.97 & 2.60 & 3.24 & 4.17 & 5.60 & 6.79 & 9.13 \\
\hline Correlations & AAA & AA & A & BBB & BB & $\mathrm{B}$ & CCC \\
\hline AAA & 1 & 0.97 & 0.91 & 0.81 & 0.49 & 0.43 & 0.35 \\
\hline AA & & 1 & 0.97 & 0.87 & 0.58 & 0.52 & 0.39 \\
\hline A & & & 1 & 0.95 & 0.73 & 0.67 & 0.54 \\
\hline BBB & & & & 1 & 0.89 & 0.84 & 0.74 \\
\hline BB & & & & & 1 & 0.95 & 0.87 \\
\hline $\mathrm{B}$ & & & & & & 1 & 0.94 \\
\hline \multicolumn{8}{|c|}{ PANEL B: Annualized Corporate Bond Returns } \\
\hline & AAA & AA & A & BBB & BB & B & CCC \\
\hline Mean & 2.35 & 2.08 & 1.84 & 1.50 & 1.25 & 1.15 & 0.56 \\
\hline Volatility & 7.57 & 7.04 & 7.58 & 7.97 & 13.50 & 18.54 & 37.87 \\
\hline Skewness & -0.17 & -0.15 & -0.56 & -2.11 & -2.72 & -0.94 & -0.52 \\
\hline Exc. Kurtosis & 5.94 & 3.15 & 5.13 & 15.67 & 21.48 & 6.51 & 8.41 \\
\hline Max & 1.23 & 1.06 & 1.09 & 0.81 & 1.19 & 2.29 & 5.38 \\
\hline Min & -1.31 & -1.02 & -1.29 & -2.01 & -3.68 & -3.35 & -6.96 \\
\hline Correlations & AAA & AA & A & BBB & $\mathrm{BB}$ & $\mathrm{B}$ & CCC \\
\hline AAA & 1 & 0.86 & 0.81 & 0.63 & 0.26 & 0.18 & 0.18 \\
\hline AA & & 1 & 0.97 & 0.80 & 0.47 & 0.37 & 0.31 \\
\hline A & & & 1 & 0.88 & 0.59 & 0.51 & 0.44 \\
\hline BBB & & & & 1 & 0.71 & 0.62 & 0.53 \\
\hline BB & & & & & 1 & 0.81 & 0.74 \\
\hline B & & & & & & 1 & 0.82 \\
\hline
\end{tabular}

These statistics are based on daily data from January 1997 to January 2012 
Table 2. Descriptive statistics of macroeconomic and financial indicators

\begin{tabular}{lccccccccc}
\hline & Default & Term & IPI & Inflation & Cons. & $\begin{array}{c}\text { Stock. } \\
\text { Con. }\end{array}$ & Employ. & VIX & Illiquidity \\
\hline Mean & 2.53 & 1.75 & 1.46 & 2.59 & 1.26 & 2.60 & 0.60 & 22.67 & -1.81 \\
Volatility & 0.87 & 1.24 & 2.52 & 0.83 & 0.87 & 3.96 & 0.64 & 8.25 & 25.14 \\
Skewness & 1.56 & -0.07 & -1.72 & -1.23 & -0.23 & -0.80 & -1.25 & 1.38 & -0.54 \\
Exc. Kurtosis & 3.60 & -1.33 & 7.82 & 9.66 & 1.61 & 1.64 & 2.29 & 3.27 & 2.49 \\
Max & 6.01 & 3.70 & 25.75 & 14.60 & 11.48 & 41.28 & 4.94 & 59.89 & 344.49 \\
Min & 1.45 & -0.53 & -50.71 & -15.25 & -9.22 & -47.09 & -7.33 & 10.42 & -324.42 \\
\hline Correlations & Default & \multirow{2}{*}{ Term } & IPI & Inflation & Cons. & Stock. & Employ. & VIX & Illiquidity \\
\hline Default & 1.00 & 0.51 & -0.46 & -0.31 & -0.37 & -0.15 & -0.80 & 0.71 & 0.16 \\
Term & & 1.00 & -0.03 & -0.07 & -0.19 & 0.02 & -0.40 & 0.22 & -0.06 \\
IPI & & & 1.00 & 0.09 & 0.34 & 0.03 & 0.53 & -0.22 & -0.12 \\
Inflation & & & & 1.00 & 0.04 & 0.10 & 0.23 & -0.38 & -0.02 \\
Consumption & & & & & 1.00 & 0.14 & 0.41 & -0.21 & -0.10 \\
Stock. Con. & & & & & & 1.00 & 0.12 & -0.44 & -0.21 \\
Employment & & & & & & & 1.00 & -0.50 & -0.12 \\
VIX & & & & & & & & 1.00 & 0.25 \\
\hline Thes statistic are
\end{tabular}

These statistics are based on monthly data from January 1997 to January 2012 
Table 3. Estimates of GARCH $(1,1)$ models with a state indicator

\begin{tabular}{|c|c|c|c|c|c|c|}
\hline & \multicolumn{3}{|c|}{ AAA } & \multicolumn{3}{|c|}{ CCC } \\
\hline & $\begin{array}{c}\text { Indicator } \\
\text { Coefficient }\end{array}$ & $\begin{array}{c}\text { Log- } \\
\text { Likelihood }\end{array}$ & $\begin{array}{l}\text { Likelihood } \\
\text { Ratio }\end{array}$ & $\begin{array}{c}\text { Indicator } \\
\text { Coefficient }\end{array}$ & $\begin{array}{c}\text { Log- } \\
\text { Likelihood }\end{array}$ & $\begin{array}{c}\text { Likelihood } \\
\text { Ratio }\end{array}$ \\
\hline Default & $\begin{array}{c}0.0268 \\
(1.33)\end{array}$ & 457.29 & $\begin{array}{c}23.18 \\
(0.000)\end{array}$ & $\begin{array}{c}0.3697 \\
(3.41)\end{array}$ & 212.19 & $\begin{array}{c}28.42 \\
(0.000)\end{array}$ \\
\hline Term & $\begin{array}{c}0.0035 \\
(1.31)\end{array}$ & 449.30 & $\begin{array}{c}7.20 \\
(0.007)\end{array}$ & $\begin{array}{c}0.0651 \\
(2.66)\end{array}$ & 199.20 & $\begin{array}{c}2.44 \\
(0.118)\end{array}$ \\
\hline IPI & $\begin{array}{c}-0.0084 \\
(-3.85)\end{array}$ & 459.69 & $\begin{array}{c}27.98 \\
(0.000)\end{array}$ & $\begin{array}{c}-0.0443 \\
(-1.67)\end{array}$ & 198.84 & $\begin{array}{c}1.72 \\
(0.190)\end{array}$ \\
\hline Inflation & $\begin{array}{l}0.100 \\
(0.94)\end{array}$ & 446.34 & $\begin{array}{c}1.28 \\
(0.258)\end{array}$ & $\begin{array}{c}-0.2371 \\
(-1.68)\end{array}$ & 200.45 & $\begin{array}{c}4.94 \\
(0.026)\end{array}$ \\
\hline Consumption & $\begin{array}{c}-0.0156 \\
(-2.64)\end{array}$ & 452.86 & $\begin{array}{c}14.32 \\
(0.000)\end{array}$ & $\begin{array}{l}-0.4487 \\
(-3.25)\end{array}$ & 203.03 & $\begin{array}{c}10.10 \\
(0.001)\end{array}$ \\
\hline $\begin{array}{l}\text { Stockholder } \\
\text { Consumption }\end{array}$ & $\begin{array}{c}-0.0048 \\
(-2.31)\end{array}$ & 459.01 & $\begin{array}{c}26.62 \\
(0.000)\end{array}$ & $\begin{array}{c}-0.0870 \\
(-4.08)\end{array}$ & 209.04 & $\begin{array}{c}22.12 \\
(0.000)\end{array}$ \\
\hline Employment & $\begin{array}{c}-0.0409 \\
(-2.31)\end{array}$ & 456.41 & $\begin{array}{c}21.42 \\
(0.000)\end{array}$ & $\begin{array}{c}-0.5995 \\
(-2.69)\end{array}$ & 201.78 & $\begin{array}{c}7.60 \\
(0.006)\end{array}$ \\
\hline VIX & $\begin{array}{l}0.0028 \\
(4.27)\end{array}$ & 453.96 & $\begin{array}{c}16.52 \\
(0.000)\end{array}$ & $\begin{array}{l}0.0268 \\
(4.25)\end{array}$ & 219.03 & $\begin{array}{c}42.10 \\
(0.000)\end{array}$ \\
\hline Illiquidity & $\begin{array}{l}0.0017 \\
(3.75)\end{array}$ & 451.98 & $\begin{array}{c}12.56 \\
(0.000)\end{array}$ & $\begin{array}{l}0.0171 \\
(4.05)\end{array}$ & 204.66 & $\begin{array}{c}13.36 \\
(0.000)\end{array}$ \\
\hline $\begin{array}{l}\text { Consumption } \\
\text { Volatility }\end{array}$ & $\begin{array}{c}0.1252 \\
(3.97)\end{array}$ & 455.26 & $\begin{array}{c}19.12 \\
(0.000)\end{array}$ & $\begin{array}{l}2.1797 \\
(3.47)\end{array}$ & 203.49 & $\begin{array}{c}11.02 \\
(0.001)\end{array}$ \\
\hline $\begin{array}{l}\text { Stock. Con. } \\
\text { Volatility }\end{array}$ & $\begin{array}{l}0.0117 \\
(2.77)\end{array}$ & 453.15 & $\begin{array}{c}14.90 \\
(0.000)\end{array}$ & $\begin{array}{c}0.2645 \\
(5.16)\end{array}$ & 216.18 & $\begin{array}{c}36.40 \\
(0.000)\end{array}$ \\
\hline
\end{tabular}

This table provides estimates of the GARCH $(1,1)$ model for AAA and CCC corporate bonds with a representative macroeconomic or financial variable indicated in column 1 as a volatility factor. Column 2 shows estimated coefficients for the indicator with $t$-statistics in parentheses, the log-likelihood of the GARCH model, and $p$-values for the likelihood ratio test in parentheses. The maximized log-likelihood function for the base case (without the additional factor) is 445.70 and 197.98 for AAA or CCC bonds, respectively. Data from January 1997 to January 2012. 
Table 4.a. Estimates of the GARCH-MIDAS volatility specification with Default

\begin{tabular}{lccccccccc}
\hline & $\omega_{1}$ & $\omega_{2}$ & $m$ & $\theta$ & $\alpha$ & $\beta$ & $\mu$ & LogLike. & L. Ratio \\
\hline \multirow{2}{*}{ AAA } & 151.244 & 7059.68 & -12.208 & 48.616 & 0.049 & 0.920 & $7.09 \mathrm{E}-05$ & \multirow{2}{*}{16166.9} & 32.179 \\
& $(24.321)$ & $(1129.31)$ & $(0.121)$ & $(4.339)$ & $(0.005)$ & $(0.009)$ & $(5.97 \mathrm{E}-05)$ & {$[0.000]$} \\
AA & 6.960 & 0.500 & -10.127 & 37.331 & 0.030 & 0.965 & $6.75 \mathrm{E}-05$ & 16163.0 & 6.233 \\
& $(21.756)$ & $(2.494)$ & $(0.257)$ & $(11.992)$ & $(0.003)$ & $(0.003)$ & $(5.89 \mathrm{E}-05)$ & {$[0.101]$} \\
A & -0.731 & 4.374 & -11.733 & 29.320 & 0.038 & 0.949 & $5.43 \mathrm{E}-05$ & 16205.7 & 5.115 \\
& $(3.284)$ & $(48.260)$ & $(0.225)$ & $(8.759)$ & $(0.004)$ & $(0.005)$ & $(5.83 \mathrm{E}-05)$ & {$[0.164]$} \\
BBB & 4.737 & 159.494 & -11.801 & 30.273 & 0.040 & 0.936 & $6.5 \mathrm{E}-05$ & 16259.6 & 9.594 \\
& $(17.647)$ & $(582.973)$ & $(0.134)$ & $(4.844)$ & $(0.004)$ & $(0.007)$ & $(5.93 \mathrm{E}-05)$ & {$[0.022]$} \\
BB & -19.664 & 69.547 & -12.941 & 80.320 & 0.055 & 0.856 & $1.53 \mathrm{E}-05$ & 16123.5 & 323.814 \\
& $(2.7 \mathrm{E}+10)$ & $(8.9 \mathrm{E}+11)$ & $(0.059)$ & $(2.178)$ & $(0.002)$ & $(0.004)$ & $(6.16 \mathrm{E}-05)$ & & {$[0.000]$} \\
B & -32.653 & 136.533 & -13.272 & 113.841 & 0.218 & 0.656 & 0.000153 & 15652.1 & 268.227 \\
& $(1.0 \mathrm{E}+11)$ & $(3.2 \mathrm{E}+12)$ & $(0.057)$ & $(1.971)$ & $(0.008)$ & $(0.009)$ & $(5.02 \mathrm{E}-05)$ & {$[0.000]$} \\
CCC & -2.952 & -2.993 & -14.871 & 182.167 & 0.009 & 0.981 & $5.61 \mathrm{E}-05$ & 12537.0 & 130.811 \\
& $(0.518)$ & $(0.516)$ & $(0.152)$ & $(6.106)$ & $(0.000)$ & $(0.000)$ & $(9.05 \mathrm{E}-05)$ & {$[0.000]$} \\
\hline
\end{tabular}

This table provides estimates of the GARCH-MIDAS model for the conditional variance of corporate bond returns where the long-run component is modeled as a function of past values of the state variable indicated in each table (the default spread in this case). The weighting scheme is the "Beta" function and the number of lags is determined to maximize likelihood. Numbers in parenthesis are standard errors. Column 9 reports the negative of the log-likelihood value at the optimum, and the last column provides the likelihood ratio test for the comparison of the estimated model with the standard GARCH model, with its $p$-value in brackets. Daily data from January 1997 to January 2012

Table 4.b. Estimates of the GARCH-MIDAS volatility specification with Term

\begin{tabular}{|c|c|c|c|c|c|c|c|c|c|}
\hline & $\omega_{1}$ & $\omega_{2}$ & $m$ & $\theta$ & $\alpha$ & $\beta$ & $\mu$ & LogLike. & L. Ratio \\
\hline AAA & $\begin{array}{c}2.885 \\
(2.133)\end{array}$ & & & & & $\begin{array}{c}0.926 \\
(0.008)\end{array}$ & & 16161.25 & \\
\hline AA & $\begin{array}{r}2.49 \\
(1.58\end{array}$ & & & & & & & 16169.15 & \\
\hline A & & & & & & $\begin{array}{c}0.951 \\
(0.005)\end{array}$ & & 16208.89 & \\
\hline BBB & $\begin{array}{c}3.472 \\
(2.479)\end{array}$ & & & & & $\begin{array}{c}0.946 \\
(0.006)\end{array}$ & $\begin{array}{l}5.89 \mathrm{I} \\
(5.9 \mathrm{E}\end{array}$ & 16262.72 & \\
\hline BB & $\begin{array}{c}2.030 \\
(0.171)\end{array}$ & $\begin{array}{c}1.184 \\
(0.104)\end{array}$ & $\begin{array}{l}-7.656 \\
(0.119)\end{array}$ & $\begin{array}{r}-189 . \\
(6.25\end{array}$ & $\begin{array}{r}0.0 \\
(0.0\end{array}$ & $\begin{array}{c}0.944 \\
(0.001)\end{array}$ & $\begin{array}{l}4.09 \mathrm{E} \\
(5.3 \mathrm{E}-\end{array}$ & 16155.09 & \\
\hline B & $\begin{array}{c}1.420 \\
(0.107)\end{array}$ & $\begin{array}{c}0.695 \\
(0.062)\end{array}$ & $\begin{array}{l}-8.033 \\
(0.090)\end{array}$ & $\begin{array}{c}-127.939 \\
(2.949)\end{array}$ & $\begin{array}{c}0.221 \\
(0.007)\end{array}$ & $\begin{array}{c}0.730 \\
(0.006)\end{array}$ & $\begin{array}{l}5.36 \mathrm{E}-05 \\
(4.0 \mathrm{E}-05)\end{array}$ & 15614.13 & $\begin{array}{l}192.342 \\
{[0.000]}\end{array}$ \\
\hline ССС & $\begin{array}{c}8.075 \\
(0.860)\end{array}$ & $\begin{array}{c}9.178 \\
(1.018)\end{array}$ & $\begin{array}{c}-10.545 \\
(0.250)\end{array}$ & $\begin{array}{l}-99.646 \\
(8.471)\end{array}$ & $\begin{array}{c}0.020 \\
(0.001)\end{array}$ & $\begin{array}{c}0.974 \\
(0.000)\end{array}$ & $\begin{array}{l}2.90 \mathrm{E}-04 \\
(9.6 \mathrm{E}-05)\end{array}$ & 12506.69 & $\begin{array}{c}70.192 \\
{[0.000]}\end{array}$ \\
\hline
\end{tabular}

See notes in Table 4.a. 
Table 4.c. Estimates of the GARCH-MIDAS volatility specification with Industrial Production Growth

\begin{tabular}{lccccccccc}
\hline & $\omega_{1}$ & $\omega_{2}$ & $m$ & $\theta$ & $\alpha$ & $\beta$ & $\mu$ & LogLike. & L. Ratio \\
\hline \multirow{2}{*}{ AAA } & 1.528 & 10.051 & -10.836 & -102.979 & 0.048 & 0.931 & $7.22 \mathrm{E}-05$ & \multirow{2}{*}{16160.8} & 20.000 \\
& $(0.459)$ & $(4.115)$ & $(0.066)$ & $(12.355)$ & $(0.005)$ & $(0.007)$ & $(5.99 \mathrm{E}-05)$ & & {$[0.000]$} \\
AA & 0.827 & 9.763 & -10.817 & -86.462 & 0.028 & 0.965 & $6.38 \mathrm{E}-05$ & 16173.9 & 28.092 \\
& $(0.480)$ & $(7.829)$ & $(0.085)$ & $(14.236)$ & $(0.003)$ & $(0.004)$ & $(5.88 \mathrm{E}-05)$ & & {$[0.000]$} \\
& 0.309 & 3.815 & -10.891 & -71.763 & 0.034 & 0.957 & $5.94 \mathrm{E}-05$ & 16210.2 & 14.081 \\
A & $(0.503)$ & $(5.796)$ & $(0.097)$ & $(24.033)$ & $(0.004)$ & $(0.005)$ & $(5.83 \mathrm{E}-05)$ & & {$[0.003]$} \\
& 0.507 & 5.597 & -10.939 & -76.803 & 0.034 & 0.950 & $6.81 \mathrm{E}-05$ & 16264.6 & 19.564 \\
BBB & $(0.416)$ & $(4.687)$ & $(0.057)$ & $(14.250)$ & $(0.004)$ & $(0.006)$ & $(5.90 \mathrm{E}-05)$ & & {$[0.000]$} \\
& 3.481 & 14.862 & -10.686 & -168.698 & 0.056 & 0.882 & $7.49 \mathrm{E}-05$ & 16137.0 & 350.752 \\
BB & $(0.419)$ & $(2.136)$ & $(0.019)$ & $(6.042)$ & $(0.002)$ & $(0.005)$ & $(5.47 \mathrm{E}-05)$ & & {$[0.000]$} \\
& 2.751 & 46.666 & -10.033 & -182.226 & 0.110 & 0.860 & $1.52 \mathrm{E}-04$ & 15610.7 & 185.440 \\
B & $(0.224)$ & $(4.796)$ & $(0.049)$ & $(3.377)$ & $(0.002)$ & $(0.003)$ & $(5.06 \mathrm{E}-05)$ & & {$[0.000]$} \\
& 1.346 & 9.650 & -11.463 & -112.317 & 0.020 & 0.974 & $8.40 \mathrm{E}-05$ & 12485.0 & 26.751 \\
CCC & $(0.197)$ & $(2.389)$ & $(0.132)$ & $(14.285)$ & $(0.000)$ & $(0.000)$ & $(9.43 \mathrm{E}-05)$ & & {$[0.000]$} \\
\hline
\end{tabular}

See notes in Table 4.a.

Table 4.d. Estimates of the GARCH-MIDAS volatility specification with Inflation

\begin{tabular}{|c|c|c|c|c|c|c|c|c|c|}
\hline & $\omega_{1}$ & $\omega_{2}$ & $m$ & $\theta$ & $\alpha$ & $\beta$ & $\mu$ & LogLike. & L. Ratio \\
\hline AAA & $\begin{array}{c}2405.62 \\
(6.0 \mathrm{E}+08)\end{array}$ & $\begin{array}{c}74.807 \\
(1.9 \mathrm{E}+07)\end{array}$ & $\begin{array}{l}-11.020 \\
(0.122)\end{array}$ & $\begin{array}{c}46.579 \\
(16.552)\end{array}$ & $\begin{array}{c}0.045 \\
(0.004)\end{array}$ & $\begin{array}{c}0.946 \\
(0.004)\end{array}$ & $\begin{array}{c}6.62 \mathrm{E}-05 \\
(5.99 \mathrm{E}-05)\end{array}$ & 16152.9 & $\begin{array}{c}4.124 \\
{[0.248]}\end{array}$ \\
\hline AA & $\begin{array}{c}1.523 \\
(7.273)\end{array}$ & $\begin{array}{c}0.189 \\
(1.314)\end{array}$ & $\begin{array}{l}-11.123 \\
(0.407)\end{array}$ & $\begin{array}{c}109.891 \\
(177.790)\end{array}$ & $\begin{array}{c}0.031 \\
(0.003)\end{array}$ & $\begin{array}{c}0.965 \\
(0.003)\end{array}$ & $\begin{array}{c}6.79 \mathrm{E}-05 \\
(5.85 \mathrm{E}-05)\end{array}$ & 16161.3 & $\begin{array}{c}2.836 \\
{[0.418]}\end{array}$ \\
\hline A & $\begin{array}{c}3.074 \\
(49.415)\end{array}$ & $\begin{array}{c}0.562 \\
(5.458)\end{array}$ & $\begin{array}{l}-11.037 \\
(0.415)\end{array}$ & $\begin{array}{c}30.593 \\
(189.946)\end{array}$ & $\begin{array}{c}0.038 \\
(0.003)\end{array}$ & $\begin{array}{c}0.955 \\
(0.004)\end{array}$ & $\begin{array}{c}5.46 \mathrm{E}-05 \\
(5.81 \mathrm{E}-05)\end{array}$ & 16203.2 & $\begin{array}{c}0.132 \\
{[0.988]}\end{array}$ \\
\hline BBB & $\begin{array}{c}5.336 \\
(60.405)\end{array}$ & $\begin{array}{c}2.287 \\
(18.907)\end{array}$ & $\begin{array}{l}-11.052 \\
(0.337)\end{array}$ & $\begin{array}{c}22.009 \\
(150.343)\end{array}$ & $\begin{array}{c}0.038 \\
(0.004)\end{array}$ & $\begin{array}{c}0.951 \\
(0.004)\end{array}$ & $\begin{array}{l}6.75 \mathrm{E}-05 \\
(5.9 \mathrm{E}-05)\end{array}$ & 16254.9 & $\begin{array}{c}0.078 \\
{[0.994]}\end{array}$ \\
\hline BB & $\begin{array}{l}221.575 \\
(25.231)\end{array}$ & $\begin{array}{l}156.620 \\
(17.538)\end{array}$ & $\begin{array}{l}-11.325 \\
(0.078)\end{array}$ & $\begin{array}{l}290.548 \\
(14.373)\end{array}$ & $\begin{array}{c}0.019 \\
(0.000)\end{array}$ & $\begin{array}{c}0.978 \\
(0.001)\end{array}$ & $\begin{array}{c}2.7 \mathrm{E}-05 \\
(4.66 \mathrm{E}-05)\end{array}$ & 16028.0 & $\begin{array}{l}132.854 \\
{[0.000]}\end{array}$ \\
\hline B & $\begin{array}{c}2.071 \\
(0.230)\end{array}$ & $\begin{array}{c}0.973 \\
(0.097)\end{array}$ & $\begin{array}{c}-7.746 \\
(0.231)\end{array}$ & $\begin{array}{c}-1106.73 \\
(97.674)\end{array}$ & $\begin{array}{c}0.065 \\
(0.001)\end{array}$ & $\begin{array}{c}0.929 \\
(0.001)\end{array}$ & $\begin{array}{c}7.81 \mathrm{E}-05 \\
(5.26 \mathrm{E}-05)\end{array}$ & 15528.0 & $\begin{array}{l}20.031 \\
{[0.000]}\end{array}$ \\
\hline ССС & $\begin{array}{c}2.522 \\
(0.238)\end{array}$ & $\begin{array}{c}3.734 \\
(0.444) \\
\end{array}$ & $\begin{array}{l}-15.206 \\
(0.327) \\
\end{array}$ & $\begin{array}{c}1335.57 \\
(133.735)\end{array}$ & $\begin{array}{c}0.020 \\
(0.000)\end{array}$ & $\begin{array}{c}0.974 \\
(0.000)\end{array}$ & $\begin{array}{c}8.99 \mathrm{E}-05 \\
(8.89 \mathrm{E}-05)\end{array}$ & 12489.8 & $\begin{array}{l}36.305 \\
{[0.000]}\end{array}$ \\
\hline
\end{tabular}

See notes in Table 4.a. 
Table 4.e. Estimates of the GARCH-MIDAS volatility specification with Consumption Growth

\begin{tabular}{lccccccccc}
\hline & $\omega_{1}$ & $\omega_{2}$ & $m$ & $\theta$ & $\alpha$ & $\beta$ & $\mu$ & LogLike. & L. Ratio \\
\hline \multirow{2}{*}{ AAA } & 3.334 & 12.784 & -10.624 & -323.751 & 0.050 & 0.927 & $7.30 \mathrm{E}-05$ & \multirow{2}{*}{16162.4} & 23.032 \\
& $(1.000)$ & $(5.126)$ & $(0.069)$ & $(33.276)$ & $(0.005)$ & $(0.007)$ & $(5.94 \mathrm{E}-05)$ & & {$[0.000]$} \\
AA & 3.389 & 19.340 & -10.659 & -278.012 & 0.028 & 0.965 & $5.65 \mathrm{E}-05$ & 16170.8 & 21.823 \\
& $(0.680)$ & $(5.607)$ & $(0.090)$ & $(40.443)$ & $(0.003)$ & $(0.004)$ & $(5.83 \mathrm{E}-05)$ & & {$[0.000]$} \\
$\mathrm{A}$ & 13.653 & 97.257 & -10.704 & -88.126 & 0.038 & 0.956 & $2.37 \mathrm{E}-05$ & 16207.9 & 9.534 \\
& $(6.353)$ & $(52.354)$ & $(0.161)$ & $(35.134)$ & $(0.004)$ & $(0.004)$ & $(5.86 \mathrm{E}-05)$ & & {$[0.023]$} \\
BBB & 37.332 & 298.347 & -10.942 & -85.152 & 0.034 & 0.955 & $6.58 \mathrm{E}-05$ & 16264.9 & 20.026 \\
& $(86.908)$ & $(756.864)$ & $(0.070)$ & $(25.270)$ & $(0.003)$ & $(0.004)$ & $(5.91 \mathrm{E}-05)$ & & {$[0.000]$} \\
BB & 5.424 & 46.331 & -10.478 & -403.830 & 0.038 & 0.897 & $7.40 \mathrm{E}-05$ & 16069.1 & 214.960 \\
& $(0.268)$ & $(2.700)$ & $(0.017)$ & $(11.866)$ & $(0.002)$ & $(0.005)$ & $(6.18 \mathrm{E}-05)$ & & {$[0.000]$} \\
B & 4.377 & 27.605 & -9.756 & -375.680 & 0.070 & 0.917 & $1.35 \mathrm{E}-04$ & 15532.2 & 28.395 \\
& $(0.336)$ & $(2.596)$ & $(0.066)$ & $(20.996)$ & $(0.001)$ & $(0.002)$ & $(4.59 \mathrm{E}-05)$ & & {$[0.000]$} \\
CCC & 4.807 & 38.894 & -11.353 & -292.740 & 0.020 & 0.974 & $-3.2 \mathrm{E}-05$ & 12491.1 & 38.947 \\
& $(0.221)$ & $(2.256)$ & $(0.142)$ & $(21.177)$ & $(0.001)$ & $(0.000)$ & $(9.34 \mathrm{E}-05)$ & & {$[0.000]$} \\
\hline
\end{tabular}

See notes in Table 4.a.

Table 4.f. Estimates of the GARCH-MIDAS volatility specification with Stockholders Consumption Growth

\begin{tabular}{lccccccccc}
\hline & $\omega_{1}$ & $\omega_{2}$ & $m$ & $\theta$ & $\alpha$ & $\beta$ & $\mu$ & LogLike. & L. Ratio \\
\hline \multirow{2}{*}{ AAA } & 1.048 & 2.157 & -10.481 & -212.898 & 0.049 & 0.930 & $6.53 \mathrm{E}-05$ & \multirow{2}{*}{16162.8} & 23.993 \\
& $(0.123)$ & $(0.511)$ & $(0.093)$ & $(31.933)$ & $(0.005)$ & $(0.007)$ & $(5.97 \mathrm{E}-05)$ & & {$[0.000]$} \\
AA & 2.258 & 14.954 & -10.820 & -42.833 & 0.028 & 0.967 & $5.88 \mathrm{E}-05$ & 16162.7 & 5.621 \\
& $(0.951)$ & $(10.138)$ & $(0.109)$ & $(19.735)$ & $(0.003)$ & $(0.003)$ & $(5.89 \mathrm{E}-05)$ & & {$[0.132]$} \\
A & 2.460 & 21.100 & -10.921 & -24.934 & 0.037 & 0.955 & $5.68 \mathrm{E}-05$ & 16204.4 & 2.500 \\
& $(1.749)$ & $(22.836)$ & $(0.110)$ & $(17.434)$ & $(0.003)$ & $(0.004)$ & $(5.82 \mathrm{E}-05)$ & & {$[0.475]$} \\
BBB & 0.368 & 0.076 & -10.882 & -53.891 & 0.038 & 0.951 & $6.38 \mathrm{E}-05$ & 16257.7 & 5.623 \\
& $(0.521)$ & $(0.515)$ & $(0.122)$ & $(41.171)$ & $(0.003)$ & $(0.004)$ & $(5.88 \mathrm{E}-05)$ & & {$[0.131]$} \\
BB & 7.673 & 7.583 & -13.895 & 303.322 & 0.022 & 0.983 & $2.09 \mathrm{E}-05$ & 16029.7 & 136.211 \\
& $(0.531)$ & $(0.474)$ & $(0.125)$ & $(15.880)$ & $(0.001)$ & $(0.000)$ & $(4.48 \mathrm{E}-05)$ & & {$[0.000]$} \\
B & 0.890 & 1.216 & -9.497 & -300.036 & 0.058 & 0.933 & $3.12 \mathrm{E}-04$ & 15535.0 & 34.058 \\
& $(0.064)$ & $(0.113)$ & $(0.090)$ & $(26.167)$ & $(0.001)$ & $(0.001)$ & $(5.24 \mathrm{E}-05)$ & & {$[0.000]$} \\
CCC & 63.987 & 342.543 & -11.977 & -42.568 & 0.026 & 0.970 & $3.05 \mathrm{E}-04$ & 12520.1 & 97.011 \\
& $(13.515)$ & $(73.070)$ & $(0.162)$ & $(3.147)$ & $(0.001)$ & $(0.000)$ & $(8.52 \mathrm{E}-05)$ & & \\
\hline
\end{tabular}

See notes in Table 4.a. 
Table 4.g. Estimates of the GARCH-MIDAS volatility specification with Employment Growth

\begin{tabular}{lccccccccc}
\hline & $\omega_{1}$ & $\omega_{2}$ & $m$ & $\theta$ & $\alpha$ & $\beta$ & $\mu$ & LogLike. & L. Ratio \\
\hline \multirow{2}{*}{ AAA } & 4.214 & 21.071 & -10.859 & -242.109 & 0.048 & 0.925 & $7.17 \mathrm{E}-05$ & \multirow{2}{*}{16163.2} & 24.696 \\
& $(2.924)$ & $(16.316)$ & $(0.054)$ & $(25.028)$ & $(0.005)$ & $(0.008)$ & $(6.00 \mathrm{E}-05)$ & & {$[0.000]$} \\
AA & 3.347 & 17.857 & -10.813 & -181.100 & 0.030 & 0.964 & $6.04 \mathrm{E}-05$ & 16165.4 & 11.144 \\
& $(2.603)$ & $(16.963)$ & $(0.084)$ & $(35.071)$ & $(0.003)$ & $(0.003)$ & $(5.88 \mathrm{E}-05)$ & & {$[0.011]$} \\
& 89.081 & 339.025 & -10.925 & -113.308 & 0.037 & 0.954 & $5.68 \mathrm{E}-05$ & 16208.2 & 10.115 \\
$\mathrm{~A}$ & $(66.620)$ & $(248.422)$ & $(0.091)$ & $(36.564)$ & $(0.004)$ & $(0.005)$ & $(5.80 \mathrm{E}-05)$ & & {$[0.018]$} \\
& 3.294 & 16.838 & -10.956 & -143.675 & 0.039 & 0.943 & $6.62 \mathrm{E}-05$ & 16259.5 & 9.226 \\
BBB & $(3.339)$ & $(19.396)$ & $(0.056)$ & $(27.884)$ & $(0.004)$ & $(0.006)$ & $(5.89 \mathrm{E}-05)$ & & {$[0.026]$} \\
& 3.860 & 17.406 & -10.712 & -427.939 & 0.056 & 0.875 & $5.57 \mathrm{E}-05$ & 16164.1 & 405.082 \\
BB & $(0.774)$ & $(3.549)$ & $(0.016)$ & $(9.938)$ & $(0.002)$ & $(0.005)$ & $(5.50 \mathrm{E}-05)$ & & {$[0.000]$} \\
& 79.306 & 1210.812 & -10.058 & -440.573 & 0.101 & 0.868 & $1.32 \mathrm{E}-04$ & 15587.6 & 139.312 \\
B & $(6.6 \mathrm{E}+04)$ & $(1.0 \mathrm{E}+06)$ & $(0.046)$ & $(9.266)$ & $(0.002)$ & $(0.003)$ & $(4.90 \mathrm{E}-05)$ & & {$[0.000]$} \\
& 4.565 & 17.551 & -11.553 & -219.318 & 0.023 & 0.973 & $-1.1 \mathrm{E}-05$ & 12479.3 & 15.348 \\
CCC & $(1.771)$ & $(7.874)$ & $(0.149)$ & $(35.312)$ & $(0.001)$ & $(0.000)$ & $(8.58 \mathrm{E}-05)$ & & {$[0.002]$} \\
\hline
\end{tabular}

See notes in Table 4.a.

Table 4.h. Estimates of the GARCH-MIDAS volatility specification with VIX

\begin{tabular}{lccccccccc}
\hline & $\omega_{1}$ & $\omega_{2}$ & $m$ & $\theta$ & $\alpha$ & $\beta$ & $\mu$ & LogLike. & L. Ratio \\
\hline \multirow{2}{*}{ AAA } & 0.140 & 3.131 & -12.190 & 53.621 & 0.053 & 0.918 & $6.40 \mathrm{E}-05$ & \multirow{2}{*}{16162.4} & 23.028 \\
& $(0.678)$ & $(3.986)$ & $(0.186)$ & $(8.005)$ & $(0.005)$ & $(0.009)$ & $(5.97 \mathrm{E}-05)$ & & {$[0.000]$} \\
AA & -0.527 & 0.228 & -11.752 & 36.056 & 0.025 & 0.969 & $-1.09 \mathrm{E}-05$ & 16163.9 & 8.028 \\
& $(0.601)$ & $(1.211)$ & $(0.280)$ & $(11.891)$ & $(0.002)$ & $(0.002)$ & $(5.88 \mathrm{E}-05)$ & & {$[0.045]$} \\
A & -1.031 & -0.169 & -11.850 & 37.094 & 0.035 & 0.952 & $6.72 \mathrm{E}-05$ & 16209.7 & 12.959 \\
& $(0.832)$ & $(1.424)$ & $(0.252)$ & $(10.843)$ & $(0.004)$ & $(0.005)$ & $(5.86 \mathrm{E}-05)$ & & {$[0.005]$} \\
BBB & -1.123 & -0.174 & -11.739 & 31.200 & 0.037 & 0.945 & $6.60 \mathrm{E}-05$ & 16260.0 & 10.329 \\
& $(1.031)$ & $(1.835)$ & $(0.197)$ & $(8.776)$ & $(0.004)$ & $(0.005)$ & $(5.95 \mathrm{E}-05)$ & & {$[0.016]$} \\
BB & -35.925 & 45.053 & -12.431 & 68.832 & 0.047 & 0.876 & $2.82 \mathrm{E}-05$ & 16037.3 & 151.507 \\
& $(1.1 \mathrm{E}+11)$ & $(1.4 \mathrm{E}+12)$ & $(0.050)$ & $(2.258)$ & $(0.002)$ & $(0.004)$ & $(6.86 \mathrm{E}-05)$ & & {$[0.000]$} \\
B & -37.647 & -37.302 & -12.159 & 86.562 & 0.064 & 0.924 & $1.28 \mathrm{E}-04$ & 15558.6 & 81.377 \\
& $(5.5 \mathrm{E}+03)$ & $(5.5 \mathrm{E}+03)$ & $(0.121)$ & $(4.566)$ & $(0.001)$ & $(0.001)$ & $(5.44 \mathrm{E}-05)$ & & {$[0.000]$} \\
CCC & 5.968 & 89.374 & -11.157 & 88.364 & 0.010 & 0.987 & $-1.7 \mathrm{E}-04$ & 12520.1 & 97.088 \\
& $(2.082)$ & $(30.191)$ & $(0.062)$ & $(2.360)$ & $(0.000)$ & $(0.000)$ & $(1.31 \mathrm{E}-04)$ & & {$[0.000]$} \\
\hline
\end{tabular}

See notes in Table 4.a. 
Table 4.i. Estimates of the GARCH-MIDAS volatility specification with Illiquidity

\begin{tabular}{lccccccccc}
\hline & $\omega_{1}$ & $\omega_{2}$ & $m$ & $\theta$ & $\alpha$ & $\beta$ & $\mu$ & LogLike. & L. Ratio \\
\hline \multirow{2}{*}{ AAA } & 5.631 & 2.644 & -11.354 & 98.853 & 0.048 & 0.940 & $6.78 \mathrm{E}-06$ & \multirow{2}{*}{16154.4} & 7.041 \\
& $(5.420)$ & $(2.393)$ & $(0.137)$ & $(29.236)$ & $(0.004)$ & $(0.005)$ & $(5.96 \mathrm{E}-05)$ & & {$[0.071]$} \\
AA & 3.828 & 53.446 & -11.020 & 26.463 & 0.028 & 0.968 & $5.68 \mathrm{E}-05$ & 16162.9 & 6.030 \\
& $(2.145)$ & $(40.642)$ & $(0.140)$ & $(14.203)$ & $(0.003)$ & $(0.003)$ & $(5.92 \mathrm{E}-05)$ & & {$[0.110]$} \\
A & 0.087 & 0.719 & -11.097 & 29.689 & 0.036 & 0.957 & $3.15 \mathrm{E}-05$ & 16204.2 & 1.968 \\
& $(0.729)$ & $(1.767)$ & $(0.177)$ & $(34.467)$ & $(0.003)$ & $(0.004)$ & $(5.80 \mathrm{E}-05)$ & & {$[0.579]$} \\
BBB & -0.618 & 41.198 & -11.026 & 5.486 & 0.037 & 0.952 & $6.97 \mathrm{E}-05$ & 16255.7 & 1.756 \\
& $(73.949)$ & $(2.4 \mathrm{E}+03)$ & $(0.084)$ & $(9.336)$ & $(0.003)$ & $(0.004)$ & $(5.88 \mathrm{E}-05)$ & & {$[0.625]$} \\
BB & 1.801 & 1.187 & -12.652 & 426.982 & 0.064 & 0.911 & $4.92 \mathrm{E}-05$ & 16279.9 & 636.622 \\
& $(0.123)$ & $(0.071)$ & $(0.061)$ & $(11.003)$ & $(0.002)$ & $(0.003)$ & $(5.05 \mathrm{E}-05)$ & & {$[0.000]$} \\
B & 17.971 & 12.020 & -11.193 & 250.049 & 0.197 & 0.759 & $-1.2 \mathrm{E}-04$ & 15656.0 & 275.998 \\
& $(1.851)$ & $(1.255)$ & $(0.072)$ & $(5.850)$ & $(0.006)$ & $(0.006)$ & $(3.74 \mathrm{E}-05)$ & & {$[0.000]$} \\
CCC & 1.425 & 1.996 & -11.141 & 566.111 & 0.027 & 0.969 & $-8.8 \mathrm{E}-06$ & 12540.1 & 136.916 \\
& $(0.050)$ & $(0.060)$ & $(0.076)$ & $(10.287)$ & $(0.001)$ & $(0.000)$ & $(1.02 \mathrm{E}-04)$ & & {$[0.000]$} \\
\hline
\end{tabular}

See notes in Table 4.a.

Table 4.j. Estimates of the GARCH-MIDAS volatility specification with Volatility of Consumption Growth

\begin{tabular}{lccccccccc}
\hline & $\omega_{1}$ & $\omega_{2}$ & $m$ & $\theta$ & $\alpha$ & $\beta$ & $\mu$ & LogLike. & L. Ratio \\
\hline \multirow{2}{*}{ AAA } & 103.336 & 117.734 & -11.149 & 450.535 & 0.046 & 0.943 & $6.44 \mathrm{E}-05$ & \multirow{2}{*}{16155.2} & 8.684 \\
& $(53.592)$ & $(61.975)$ & $(0.111)$ & $(148.761)$ & $(0.004)$ & $(0.005)$ & $(5.98 \mathrm{E}-05)$ & & {$[0.034]$} \\
AA & 138.644 & 152.642 & -10.996 & 220.313 & 0.030 & 0.966 & $5.95 \mathrm{E}-05$ & 16161.8 & 3.962 \\
& $(105.746)$ & $(118.560)$ & $(0.121)$ & $(120.811)$ & $(0.002)$ & $(0.002)$ & $(5.86 \mathrm{E}-05)$ & & {$[0.266]$} \\
A & 7.027 & 10.938 & -11.290 & 649.549 & 0.038 & 0.953 & $5.98 \mathrm{E}-05$ & 16204.6 & 2.928 \\
& $(6.511)$ & $(10.812)$ & $(0.163)$ & $(309.401)$ & $(0.003)$ & $(0.004)$ & $(5.82 \mathrm{E}-05)$ & & {$[0.403]$} \\
BBB & 381.637 & 788.044 & -11.130 & 205.150 & 0.038 & 0.949 & $7.54 \mathrm{E}-05$ & 16262.2 & 14.778 \\
& $(0.401)$ & $(0.695)$ & $(0.071)$ & $(37.657)$ & $(0.003)$ & $(0.004)$ & $(5.84 \mathrm{E}-05)$ & & {$[0.002]$} \\
BB & 653.936 & 440.987 & -11.252 & 799.844 & 0.065 & 0.907 & $1.45 \mathrm{E}-04$ & 16265.0 & 606.851 \\
& $(0.170)$ & $(0.148)$ & $(0.036)$ & $(9.050)$ & $(0.002)$ & $(0.003)$ & $(4.88 \mathrm{E}-05)$ & & {$[0.000]$} \\
B & 5.290 & 10.127 & -11.630 & 3214.928 & 0.190 & 0.767 & $9.57 \mathrm{E}-05$ & 15658.5 & 281.134 \\
& $(0.266)$ & $(0.552)$ & $(0.071)$ & $(54.792)$ & $(0.006)$ & $(0.006)$ & $(4.30 \mathrm{E}-05)$ & & {$[0.000]$} \\
CCC & 228.737 & 167.646 & -12.408 & 738.075 & 0.029 & 0.968 & $8.41 \mathrm{E}-04$ & 12521.8 & 100.449 \\
& $(29.573)$ & $(21.335)$ & $(0.147)$ & $(46.869)$ & $(0.001)$ & $(0.000)$ & $(7.48 \mathrm{E}-05)$ & & \\
\hline
\end{tabular}

See notes in Table 4.a. 
Table 4.k. Estimates of the GARCH-MIDAS volatility specification with Volatility of Stockholders Consumption Growth

\begin{tabular}{lccccccccc}
\hline & $\omega_{1}$ & $\omega_{2}$ & $m$ & $\theta$ & $\alpha$ & $\beta$ & $\mu$ & LogLike. & L. Ratio \\
\hline \multirow{2}{*}{ AAA } & 3.187 & 38.532 & -11.283 & 30.547 & 0.050 & 0.931 & $6.62 \mathrm{E}-05$ & \multirow{2}{*}{16159.1} & 16.597 \\
& $(0.901)$ & $(13.578)$ & $(0.086)$ & $(5.323)$ & $(0.005)$ & $(0.007)$ & $(6.02 \mathrm{E}-05)$ & & {$[0.001]$} \\
AA & 6.806 & 108.735 & -11.058 & 13.104 & 0.027 & 0.969 & $5.77 \mathrm{E}-05$ & 16166.7 & 13.709 \\
& $(3.096)$ & $(57.863)$ & $(0.130)$ & $(4.206)$ & $(0.003)$ & $(0.003)$ & $(5.88 \mathrm{E}-05)$ & & {$[0.003]$} \\
& 15.069 & 116.531 & -11.071 & 7.618 & 0.036 & 0.956 & $5.67 \mathrm{E}-05$ & 16206.3 & 6.242 \\
$\mathrm{~A}$ & $(17.034)$ & $(144.014)$ & $(0.112)$ & $(3.718)$ & $(0.003)$ & $(0.004)$ & $(5.83 \mathrm{E}-05)$ & & {$[0.100]$} \\
BBB & 87.091 & 5.885 & -11.079 & 7.951 & 0.036 & 0.955 & $6.89 \mathrm{E}-05$ & 16258.7 & 7.781 \\
& $(144.414)$ & $(9.441)$ & $(0.085)$ & $(2.937)$ & $(0.003)$ & $(0.004)$ & $(5.86 \mathrm{E}-05)$ & & {$[0.051]$} \\
BB & 180.185 & 365.396 & -11.217 & 33.664 & 0.055 & 0.909 & $1.05 \mathrm{E}-04$ & 16136.0 & 348.835 \\
& $(18.332)$ & $(38.813)$ & $(0.030)$ & $(1.369)$ & $(0.002)$ & $(0.003)$ & $(5.18 \mathrm{E}-05)$ & & {$[0.000]$} \\
B & -3.098 & -3.315 & -10.033 & -4.642 & 0.060 & 0.935 & $1.51 \mathrm{E}-04$ & 15518.9 & 1.876 \\
& $(7.622)$ & $(7.583)$ & $(0.101)$ & $(3.289)$ & $(0.001)$ & $(0.001)$ & $(4.59 \mathrm{E}-05)$ & & {$[0.599]$} \\
CCC & -1.949 & -2.256 & -12.013 & 7.518 & 0.024 & 0.971 & $-6.7 \mathrm{E}-06$ & 12471.6 & 0.002 \\
& $(2.040)$ & $(2.006)$ & $(0.144)$ & $(3.450)$ & $(0.001)$ & $(0.000)$ & $(8.40 \mathrm{E}-05)$ & & {$[1.000]$} \\
\hline
\end{tabular}

See notes in Table 4.a. 
Table 5. The behavior of the difference of corporate bond return volatilities estimated with the MIDAS-GARCH model and the standard GARCH model during expansions and recessions

\begin{tabular}{|c|c|c|c|c|}
\hline & \multicolumn{2}{|c|}{ AAA } & \multicolumn{2}{|c|}{ CCC } \\
\hline $\begin{array}{l}\text { Macroeconomic } \\
\text { or Financial } \\
\text { Indicators }\end{array}$ & $\begin{array}{c}\alpha \\
\text { (Recession) }\end{array}$ & $\begin{array}{c}\beta \\
\text { (Normal vs. } \\
\text { Recession) }\end{array}$ & $\begin{array}{c}\alpha \\
\text { (Recession) }\end{array}$ & $\begin{array}{c}\beta \\
\text { (Normal vs. } \\
\text { Recession) }\end{array}$ \\
\hline Default & $\begin{array}{c}-0.00672 \\
(<0.00001)\end{array}$ & $\begin{array}{c}0.00513 \\
(<0.00001)\end{array}$ & $\begin{array}{c}0.00097 \\
(0.65904)\end{array}$ & $\begin{array}{c}-0.00011 \\
(0.96235)\end{array}$ \\
\hline Term & $\begin{array}{c}-0.00021 \\
(0.83790)\end{array}$ & $\begin{array}{c}0.00022 \\
(0.83851)\end{array}$ & $\begin{array}{c}-0.02321 \\
(0.01733)\end{array}$ & $\begin{array}{c}0.01817 \\
(0.06443)\end{array}$ \\
\hline IPI & $\begin{array}{c}0.00142 \\
(0.06321)\end{array}$ & $\begin{array}{c}0.00811 \\
(<0.00001)\end{array}$ & $\begin{array}{l}-0.00526 \\
(0.01718)\end{array}$ & $\begin{array}{c}0.00293 \\
(0.23032)\end{array}$ \\
\hline Inflation & $\begin{array}{c}0.00151 \\
(0.08112)\end{array}$ & $\begin{array}{c}0.00745 \\
(<0.00001)\end{array}$ & $\begin{array}{c}-0.01105 \\
(<0.00001)\end{array}$ & $\begin{array}{c}0.00682 \\
(0.00008)\end{array}$ \\
\hline Consumption & $\begin{array}{c}0.00229 \\
(0.00276)\end{array}$ & $\begin{array}{c}0.00745 \\
(<0.00001)\end{array}$ & $\begin{array}{l}-0.00139 \\
(0.56044)\end{array}$ & $\begin{array}{c}-0.00364 \\
(0.13688)\end{array}$ \\
\hline $\begin{array}{l}\text { Stockholder } \\
\text { Consumption }\end{array}$ & $\begin{array}{c}0.00161 \\
(0.05681)\end{array}$ & $\begin{array}{c}0.00721 \\
(<0.00001)\end{array}$ & $\begin{array}{c}-0.00252 \\
(0.37261)\end{array}$ & $\begin{array}{l}-0.00025 \\
(0.93246)\end{array}$ \\
\hline Employment & $\begin{array}{c}0.00245 \\
(0.00233)\end{array}$ & $\begin{array}{c}0.00778 \\
(<0.00001)\end{array}$ & $\begin{array}{l}-0.00116 \\
(0.63025)\end{array}$ & $\begin{array}{l}-0.00317 \\
(0.20950)\end{array}$ \\
\hline VIX & $\begin{array}{c}-0.00629 \\
(<0.00001)\end{array}$ & $\begin{array}{c}0.00431 \\
(<0.00001)\end{array}$ & $\begin{array}{c}-0.02064 \\
(<0.00001)\end{array}$ & $\begin{array}{c}0.01921 \\
(<0.00001)\end{array}$ \\
\hline Illiquidity & $\begin{array}{c}0.00038 \\
(0.75790)\end{array}$ & $\begin{array}{c}0.01371 \\
(<0.00001)\end{array}$ & $\begin{array}{c}0.11951 \\
(<0.00001)\end{array}$ & $\begin{array}{l}-0.09320 \\
(0.00016)\end{array}$ \\
\hline $\begin{array}{l}\text { Consumption } \\
\text { Volatility }\end{array}$ & $\begin{array}{c}0.00278 \\
(0.00126)\end{array}$ & $\begin{array}{c}0.00748 \\
(<0.00001)\end{array}$ & $\begin{array}{c}-0.01062 \\
(<0.00001)\end{array}$ & $\begin{array}{c}0.00461 \\
(0.00517)\end{array}$ \\
\hline $\begin{array}{l}\text { Stock. Con. } \\
\text { Volatility }\end{array}$ & $\begin{array}{l}-0.00062 \\
(0.40164)\end{array}$ & $\begin{array}{c}0.00554 \\
(<0.00001)\end{array}$ & $\begin{array}{c}-0.02723 \\
(<0.00001)\end{array}$ & $\begin{array}{c}0.02444 \\
(0.00013)\end{array}$ \\
\hline
\end{tabular}

OLS regression coefficients with HAC standard errors and $p$-values in parentheses from the regression,

$$
\hat{\sigma}_{t}^{G M}-\hat{\sigma}_{t}^{C n t}=\alpha+\beta \times E X P A N S I O N_{t}+u_{t},
$$

where $\hat{\sigma}_{t}^{G M}$ is the volatility generated by the GARCH-MIDAS model with the long-run component changing with the state variable indicated in the first column, $\hat{\sigma}_{t}^{C n t}$ is the volatility from the model with constant long-run component, and EXPANSION is a dummy variable that takes the value of 1 whenever the month $t$ does not belong to the NBER official recession dates, and zero otherwise. 
Table 6. Comparison of out-of-sample forecasting ability for volatility from the MIDAS-GARCH model and the GARCH model with constant long-run component

\begin{tabular}{|c|c|c|c|c|c|c|}
\hline \multicolumn{7}{|c|}{ PANEL A: AAA } \\
\hline & Default & Term & IPI & Inflation & Consumption & $\begin{array}{l}\text { Stockholder } \\
\text { Consumption }\end{array}$ \\
\hline$F$ & -92.35 & 53.08 & -613.93 & -67.27 & 629.74 & -483.67 \\
\hline$F(100)$ & -127.36 & 140.72 & -568.02 & 33.70 & 493.26 & -429.84 \\
\hline \multirow[t]{2}{*}{$F>0$} & $16 \%$ & $92 \%$ & $0 \%$ & $68 \%$ & $97 \%$ & $3 \%$ \\
\hline & Employment & VIX & Illiquidity & $\begin{array}{c}\text { Consumption } \\
\text { Volatility }\end{array}$ & $\begin{array}{c}\text { Stock. Cons. } \\
\text { Volatility }\end{array}$ & \\
\hline$F$ & -217.29 & 566.65 & -369.97 & -248.18 & -490.96 & \\
\hline$F(100)$ & -8.16 & 531.21 & -345.75 & -71.26 & -524.83 & \\
\hline$F>0$ & $49 \%$ & $94 \%$ & $0 \%$ & $31 \%$ & $0 \%$ & \\
\hline \multicolumn{7}{|c|}{ PANEL B: CCC } \\
\hline & Default & Term & IPI & Inflation & Consumption & $\begin{array}{c}\text { Stockholder } \\
\text { Consumption }\end{array}$ \\
\hline$F$ & 934.29 & 33.12 & 779.86 & -416.12 & 234.90 & 753.66 \\
\hline$F(100)$ & 825.03 & 81.09 & 544.47 & -566.65 & 85.18 & 449.79 \\
\hline \multirow[t]{2}{*}{$F>0$} & $100 \%$ & $89 \%$ & $99 \%$ & $0 \%$ & $76 \%$ & $93 \%$ \\
\hline & Employment & VIX & Illiquidity & $\begin{array}{c}\text { Consumption } \\
\text { Volatility }\end{array}$ & $\begin{array}{c}\text { Stock. Cons. } \\
\text { Volatility }\end{array}$ & \\
\hline$F$ & 829.95 & 983.91 & 613.41 & 829.89 & 1270.80 & \\
\hline$F(100)$ & 609.39 & 832.94 & -145.84 & 718.03 & 990.17 & \\
\hline$F>0$ & $100 \%$ & $100 \%$ & $48 \%$ & $100 \%$ & $100 \%$ & \\
\hline
\end{tabular}

The estimation period employs daily information between January 1997 and August 2004, and the forecasting period includes all days between September 2004 and January 2012. The statistic for the comparison is:

$$
F=\left(T_{2}-21\right) \frac{M S E_{1}-M S E_{2}}{M S E_{2}},
$$

where $M S E_{1}$ and $M S E_{2}$ refer to the mean squared forecasting error for the model with constant long-run component in volatility, and for the GARCH-MIDAS model with the long-run component determined by the indicated state variable, respectively. Rows denoted by $F$ provide the value of the statistic obtained with one simulated series for the shock. Rows denoted by $F$ (100) provide the mean value of the 100 statistics from 100 simulated series for the shock. $F>0$ indicates the number of cases with positive value. 
Figure 1. Annualized corporate bond yields by credit rating

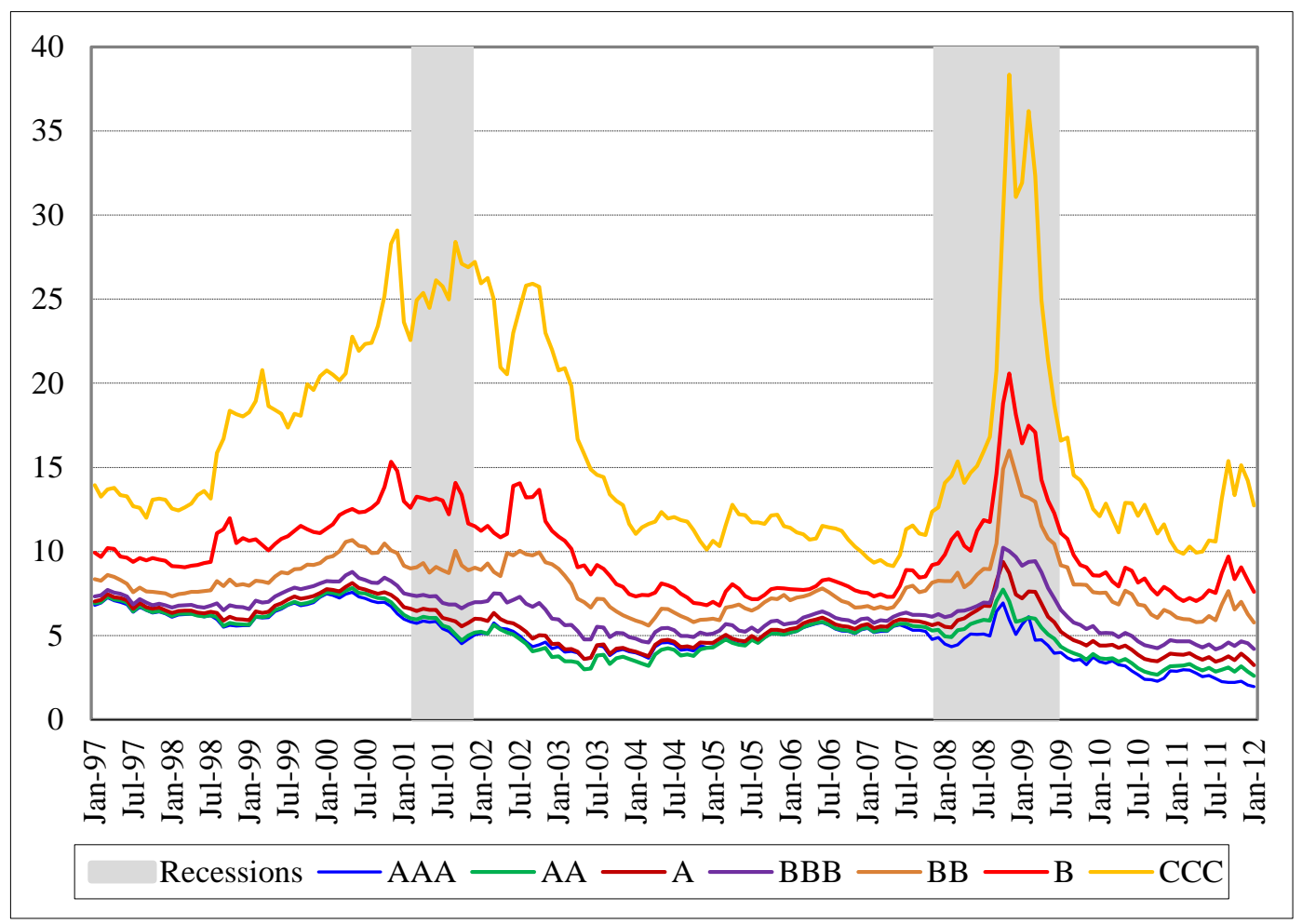


Figure 2. Annual consumption, stockholder consumption, and employment growth rates

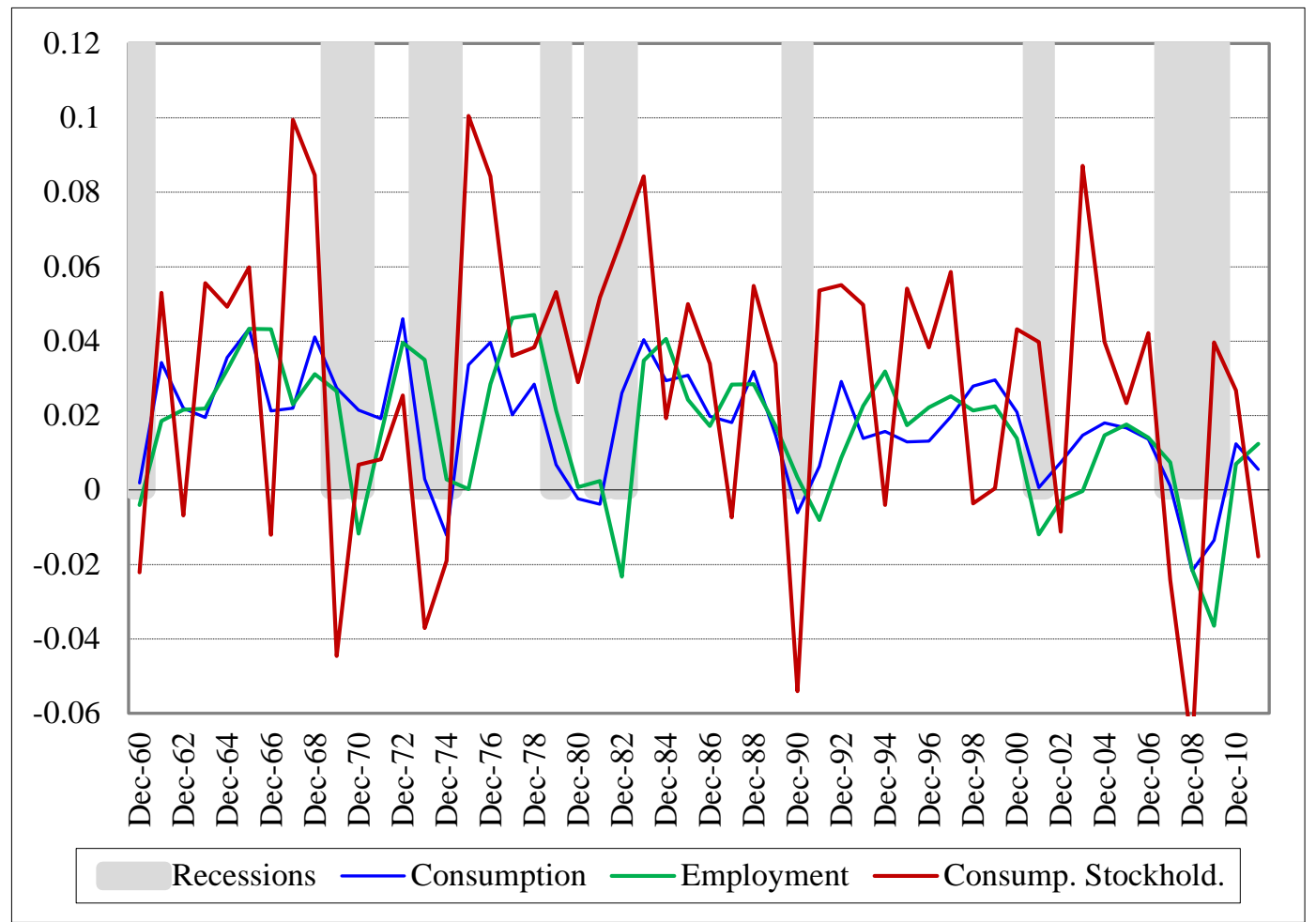


Figure 3. Annualized conditional volatilities for representative corporate bonds

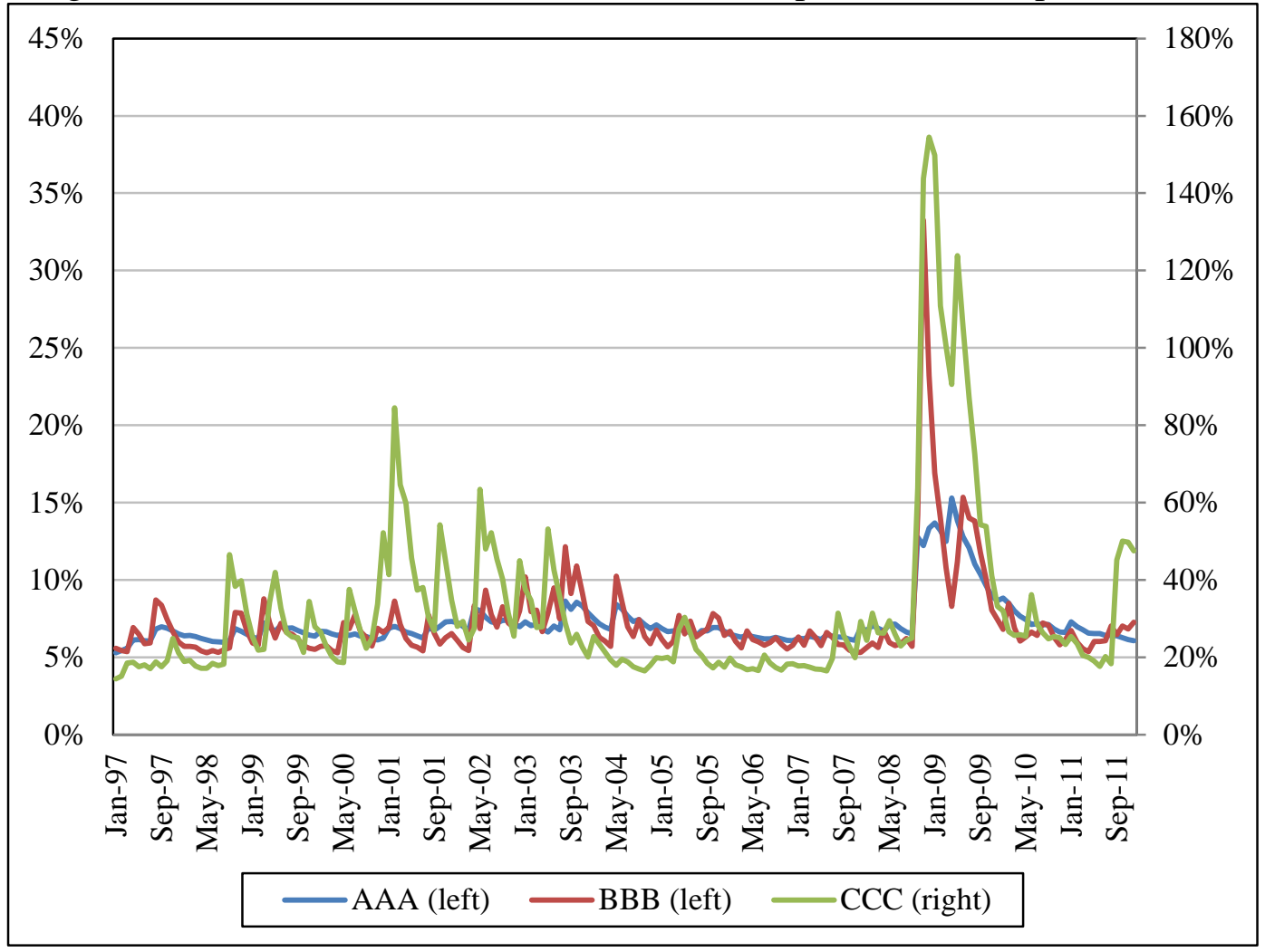


Figure 4.a Simple autocorrelation functions of squared AAA corporate bond returns

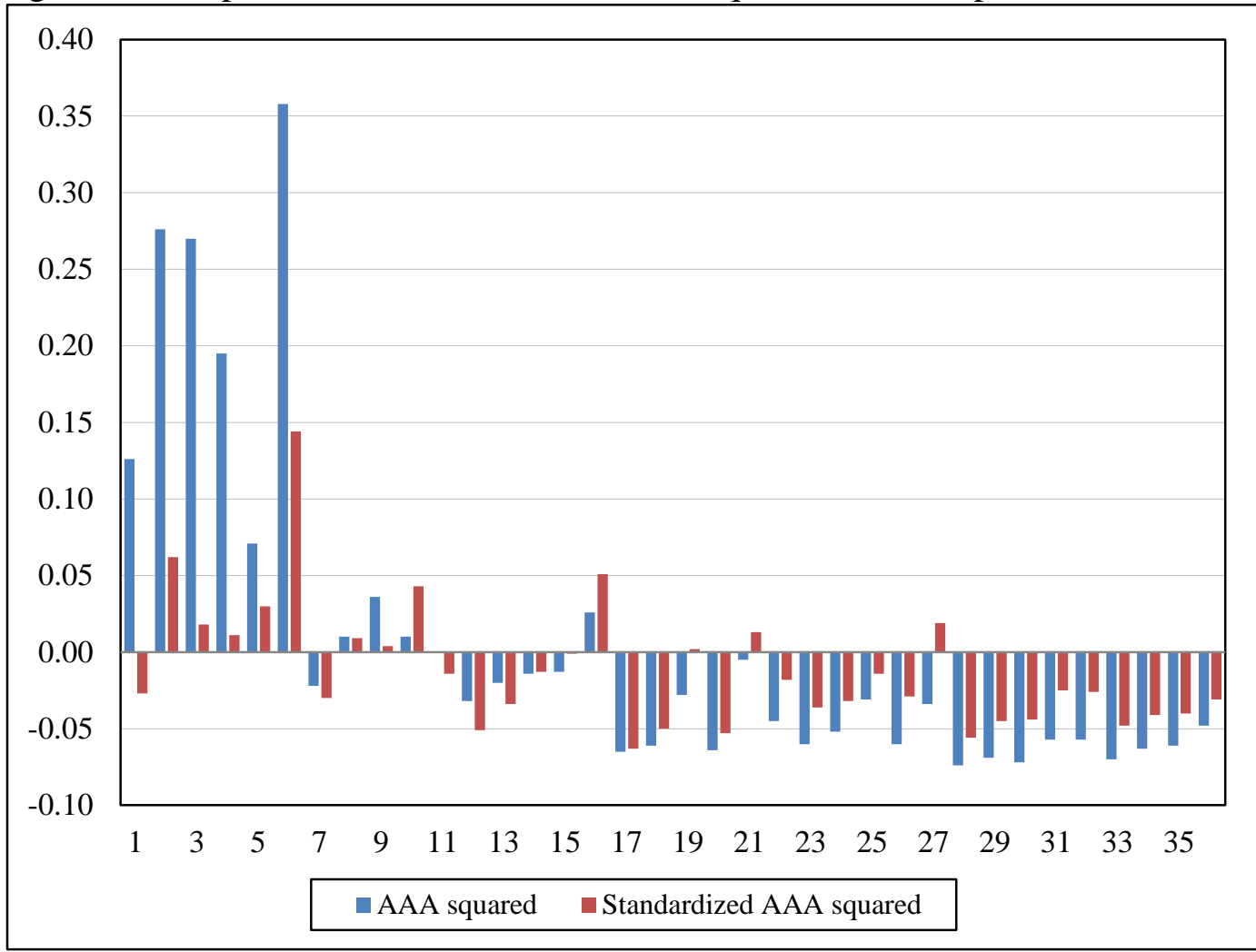

Figure 4.b Simple autocorrelation functions of squared CCC corporate bond returns

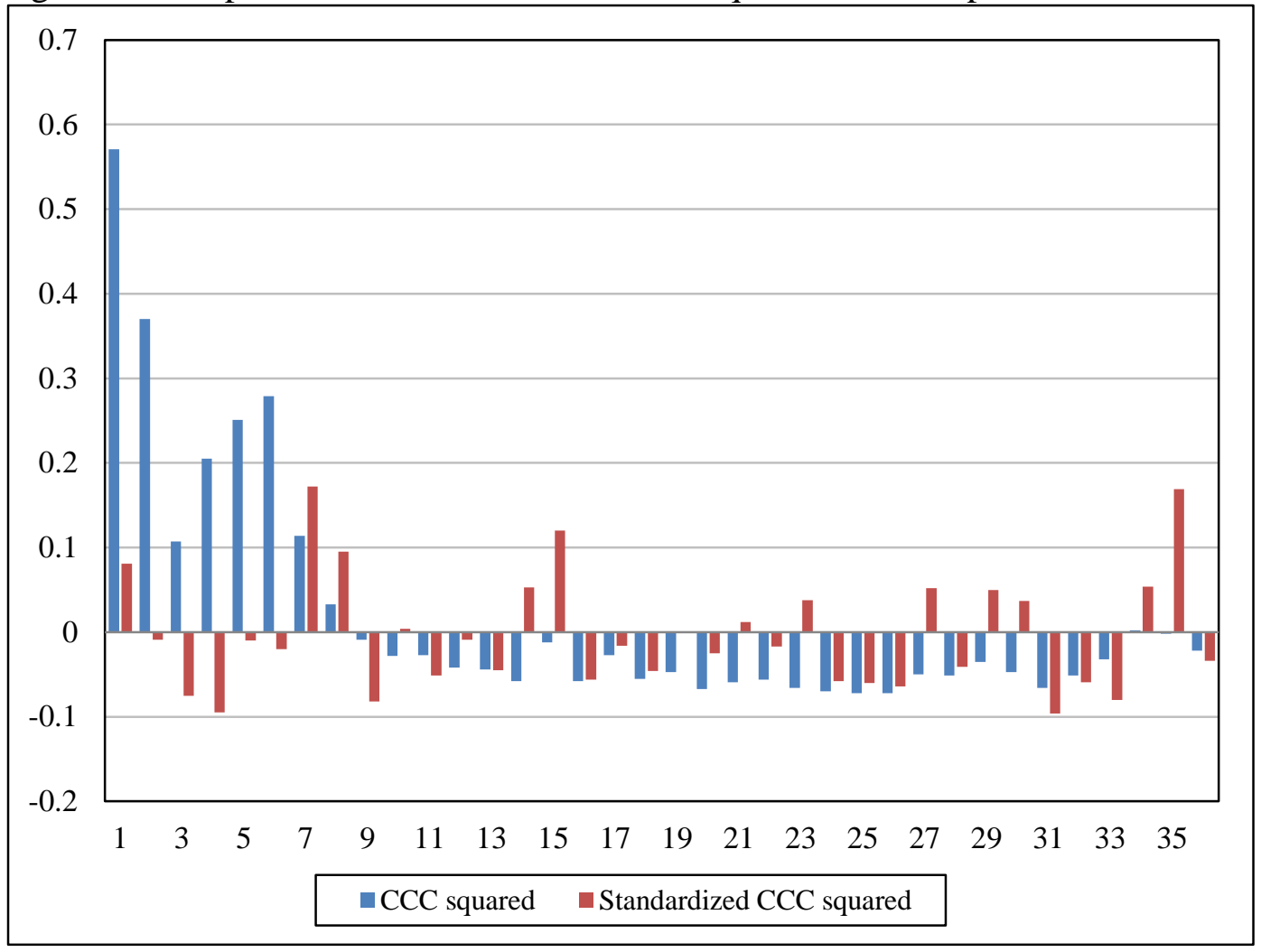


Figure 5. Dynamic conditional correlations between pairs of corporate bond returns

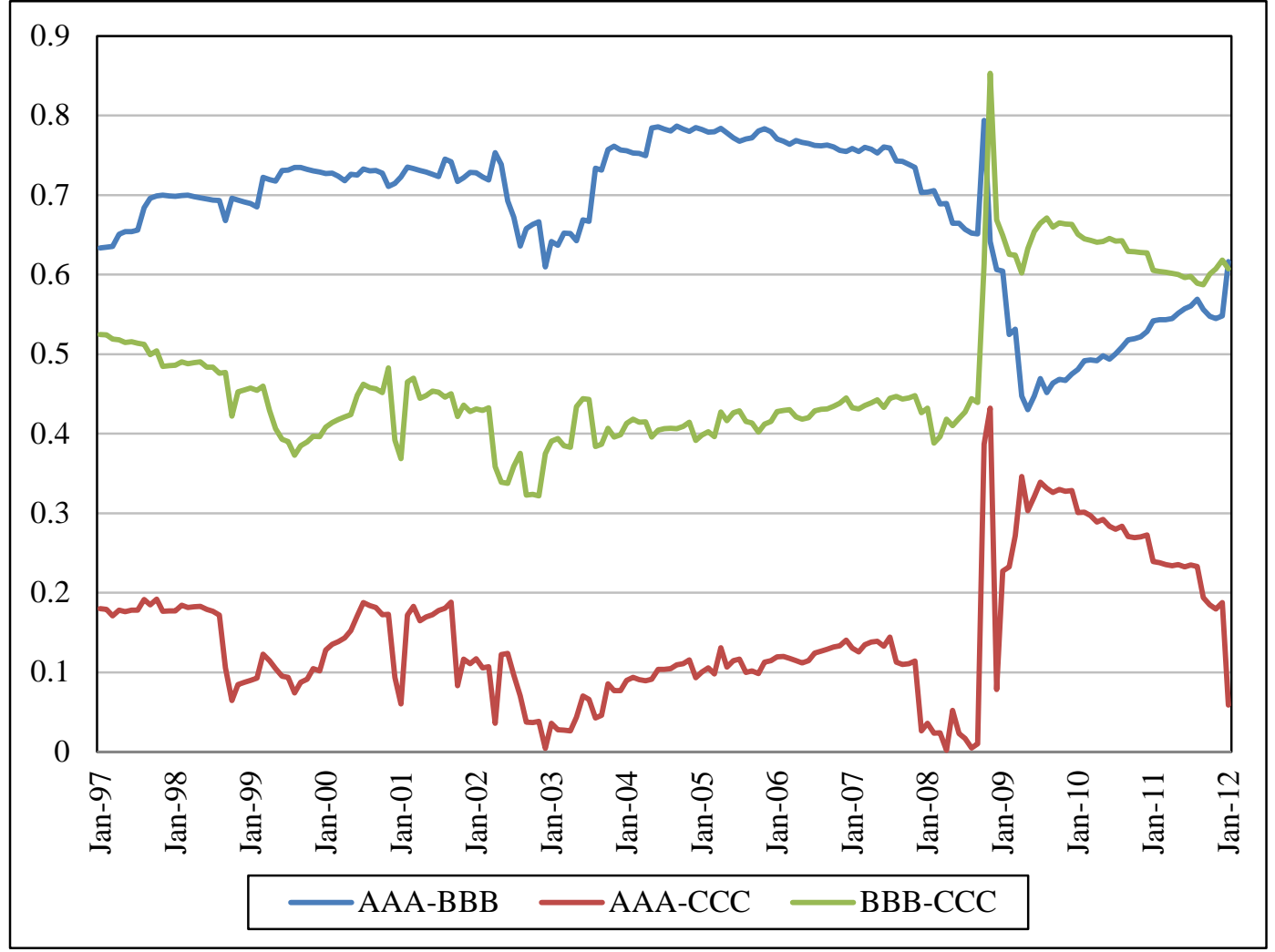


Figure 6.a. Slope parameter estimates of the long-run component $(\theta)$ with state variable indicating bad news

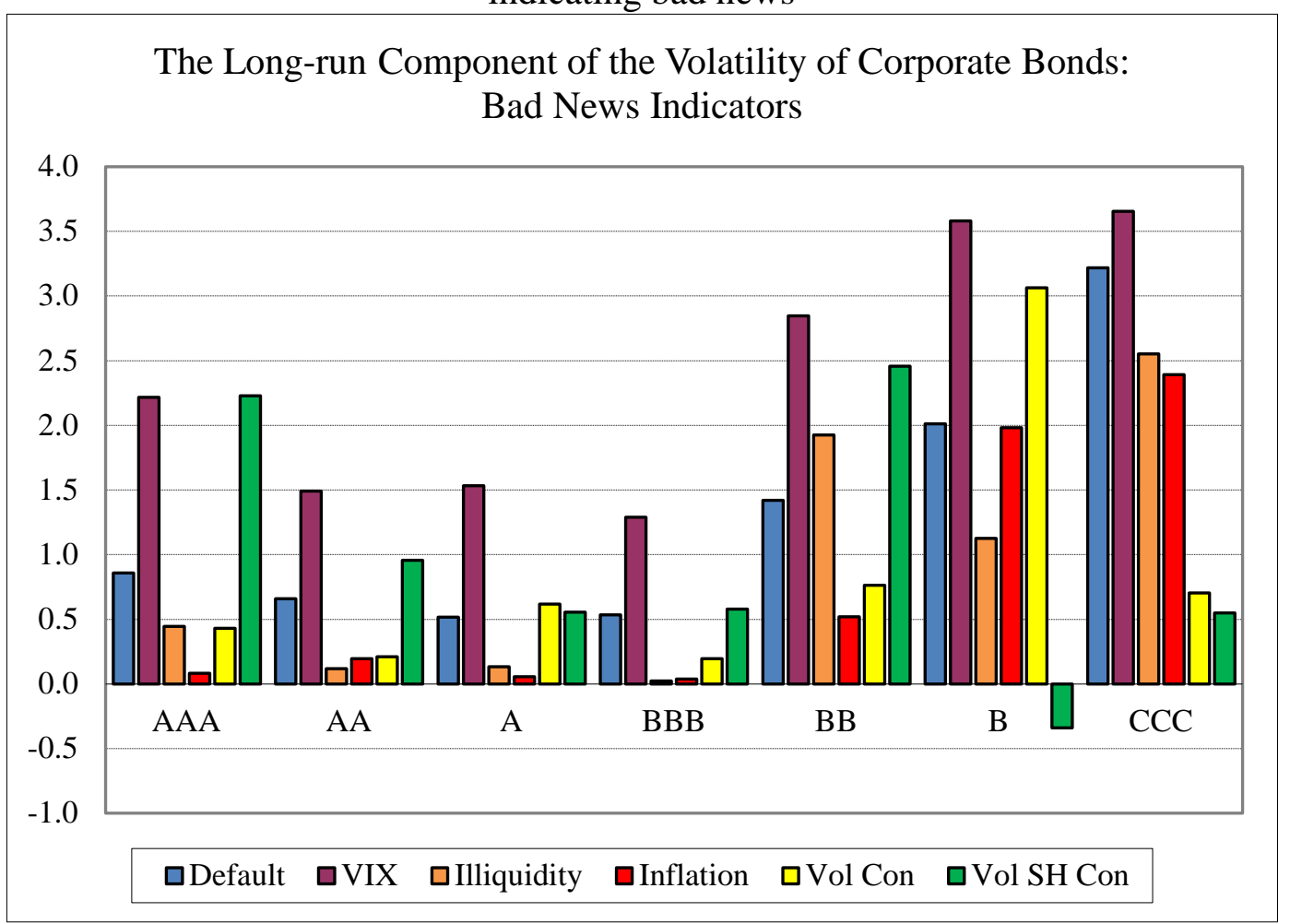

Figure 6.b. Slope parameter estimates of the long-run component $(\theta)$ with state variable indicating good news

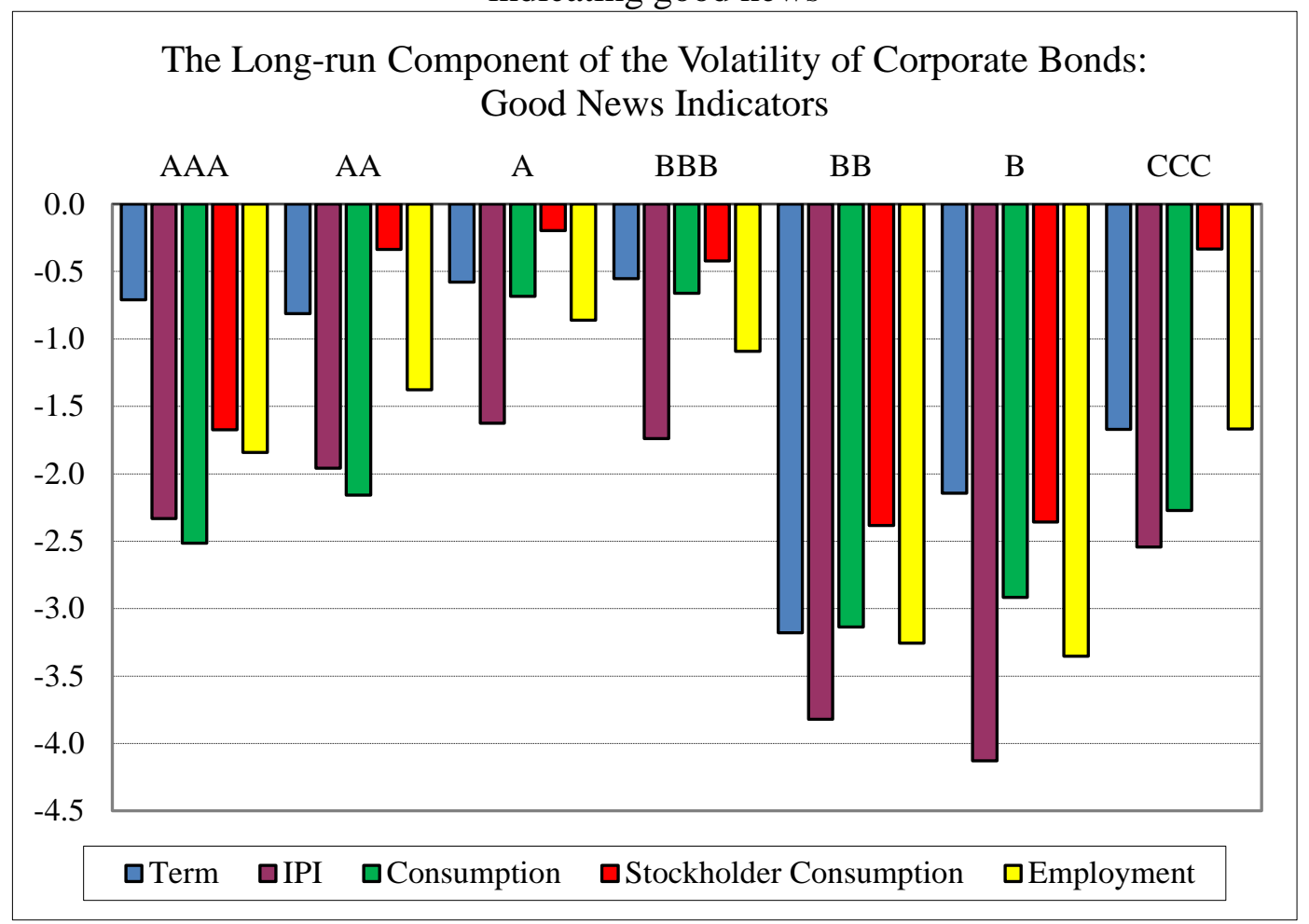


Figure 7.a. Differences in volatilities generated by the GARCH-MIDAS model with state indicator and the constant long-run component volatility model. AAA rated bonds.

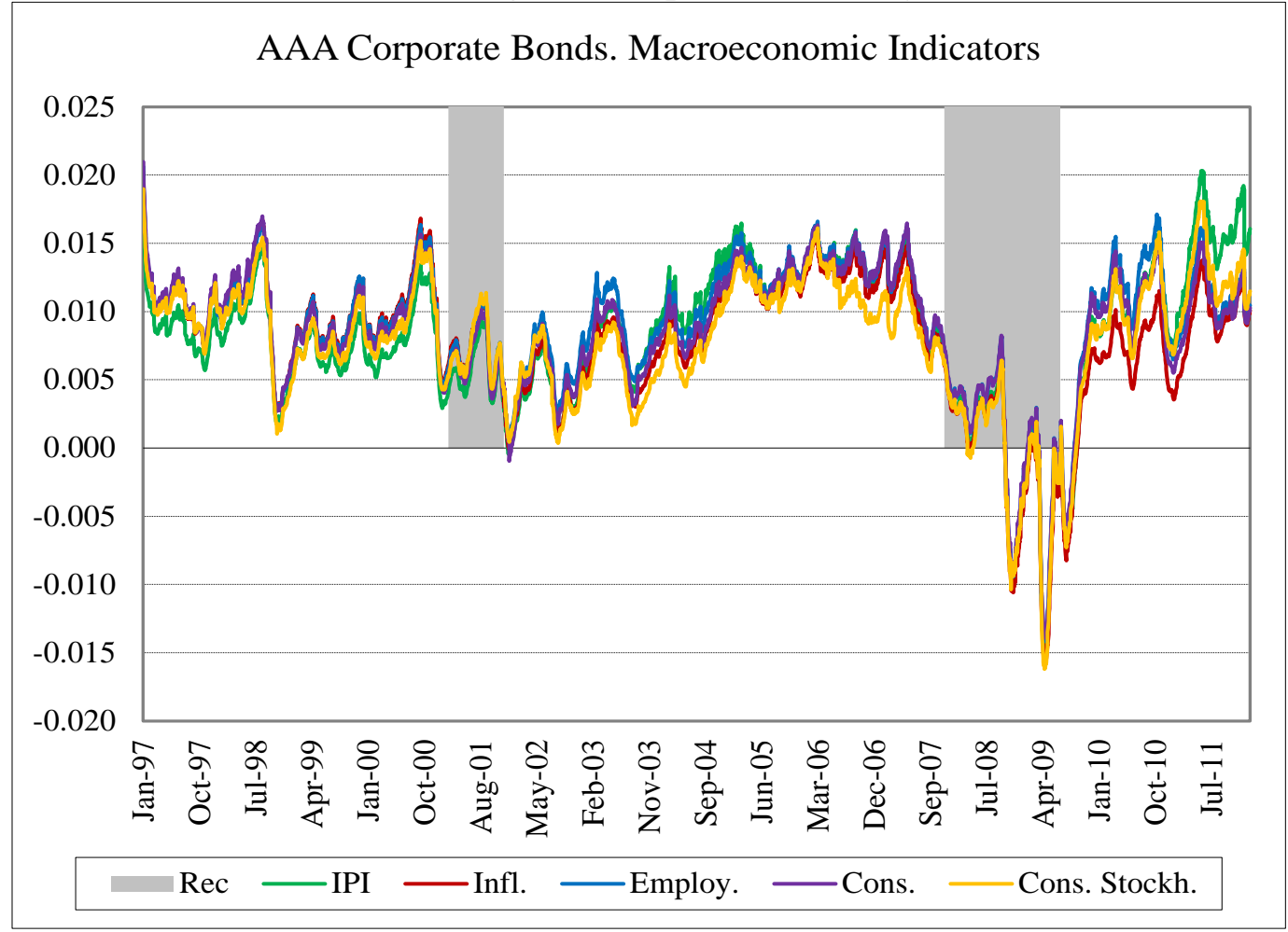

Figure 7.b. Differences in volatilities generated by the GARCH-MIDAS model with state indicator and the constant long-run component volatility model. CCC rated bonds.

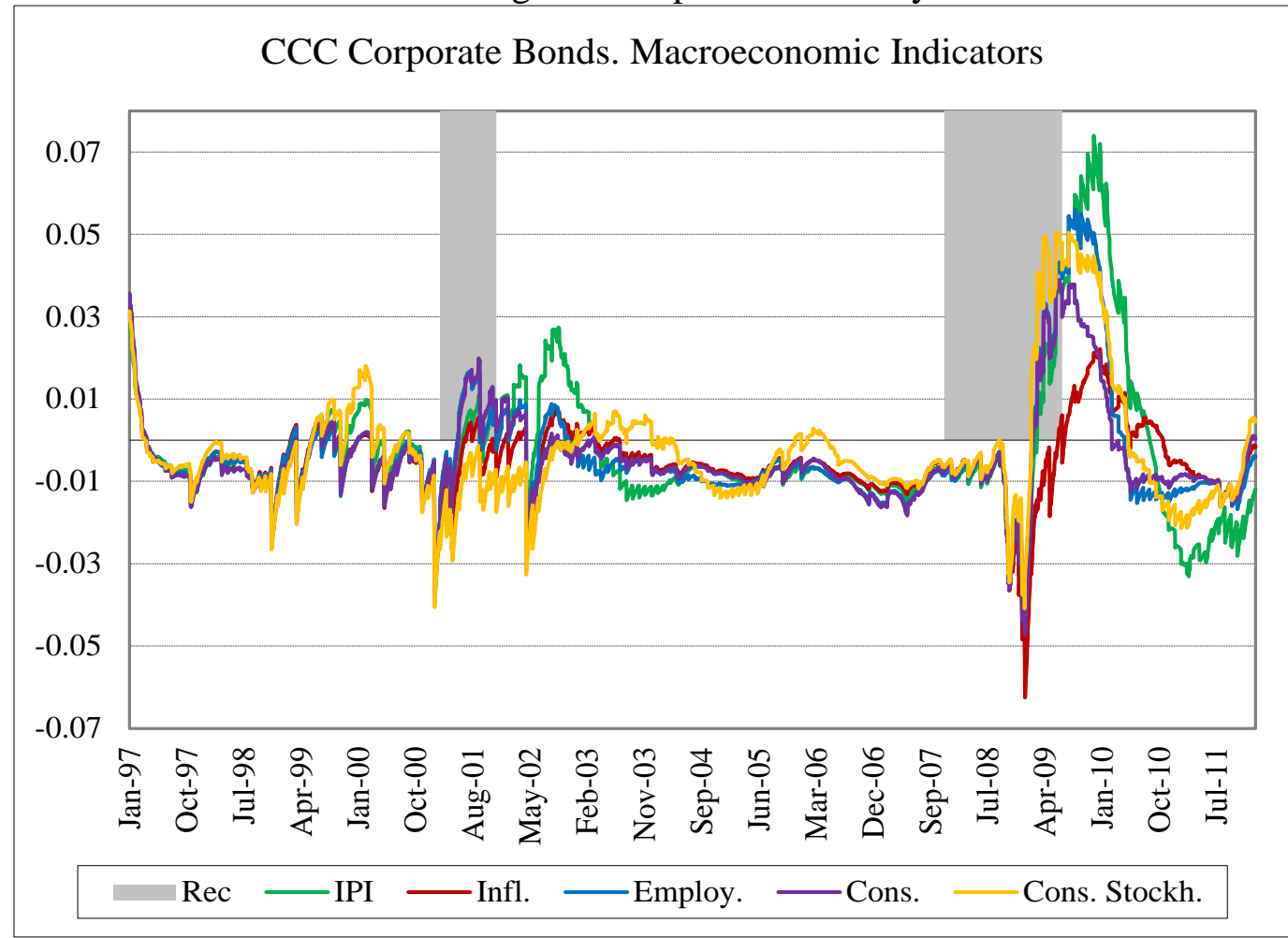


Figure 8.a. Differences in volatilities generated by the GARCH-MIDAS model with a financial indicator and the constant long-run component volatility model. AAA rated bonds.

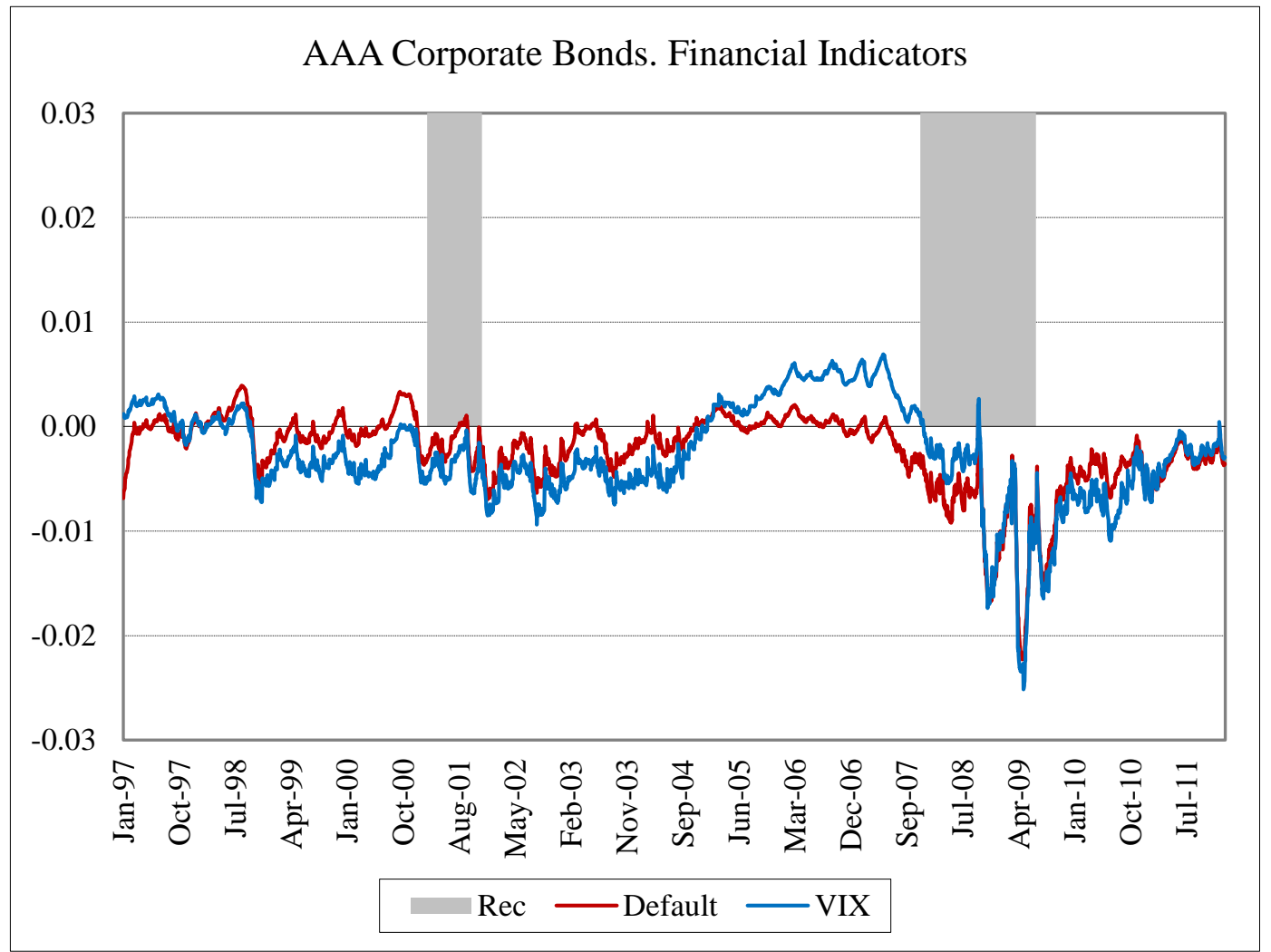

Figure 8.b. Differences in volatilities generated by the GARCH-MIDAS model with a financial indicator and the constant long-run component volatility model. CCC rated bonds.

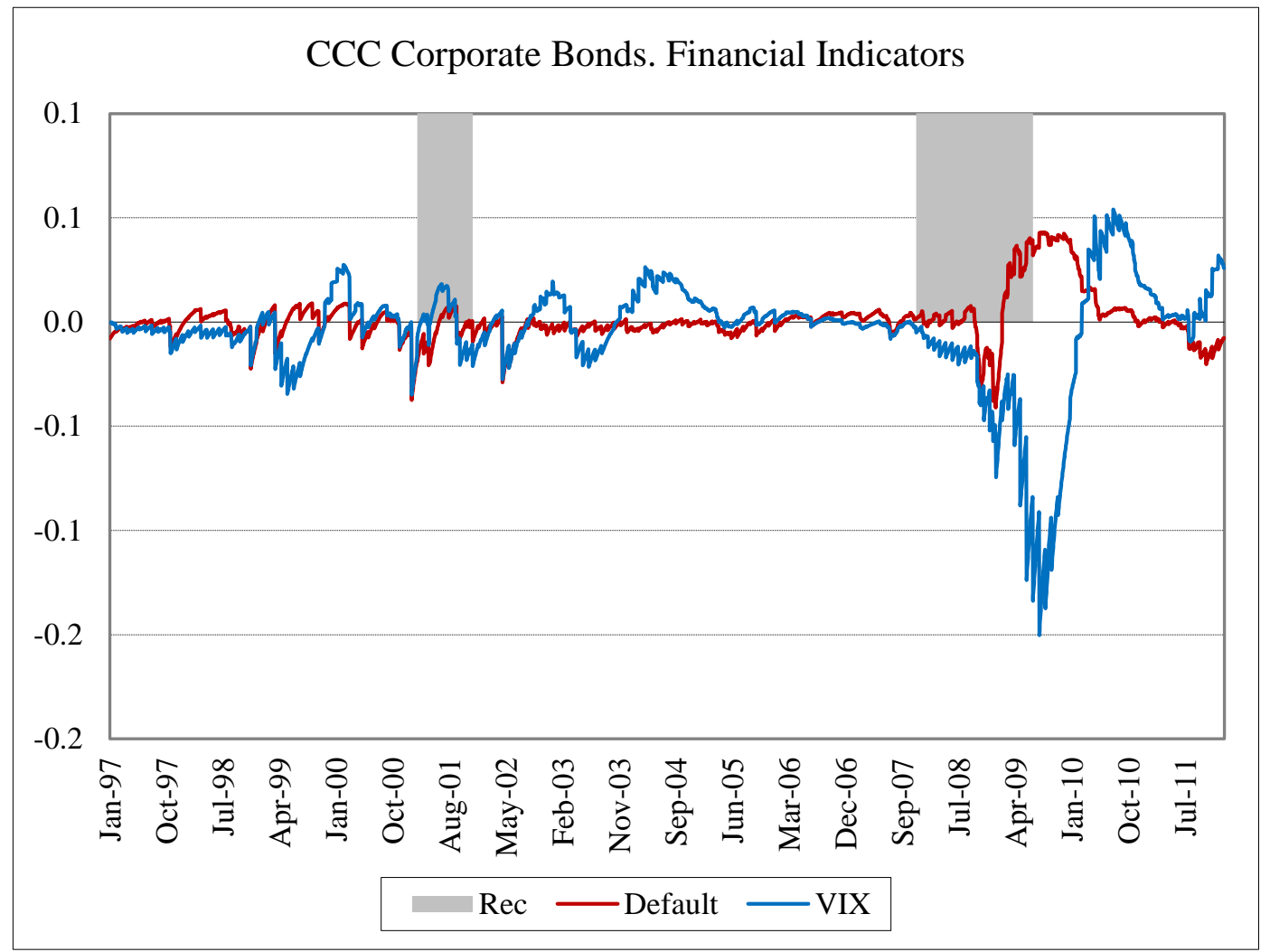


Figure 9.a. Out-of-sample MSE for the Constant Long Term Component Volatility and the GARCH-MIDAS Volatility with Selected Indicators. AAA rated bonds.

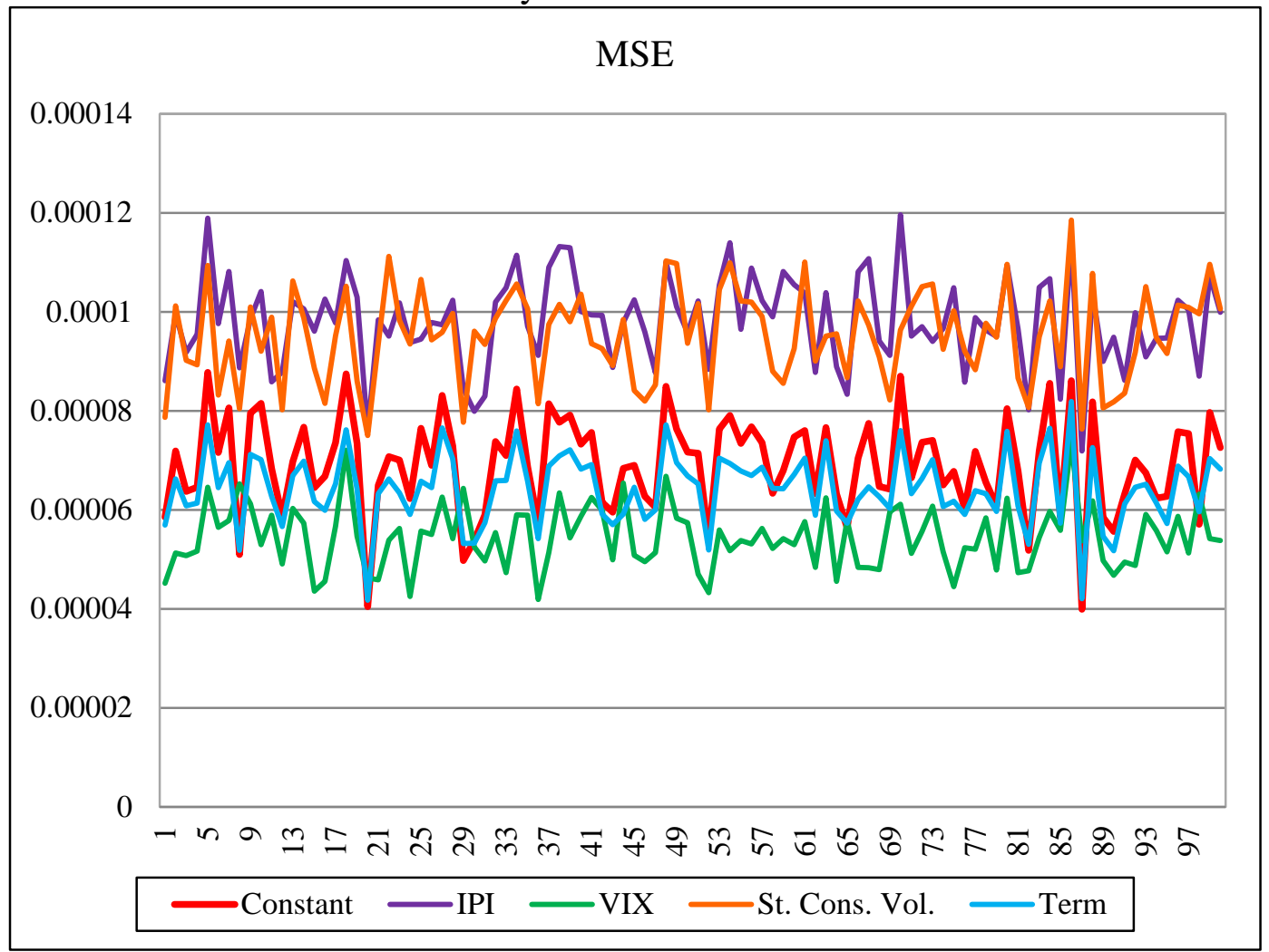

Figure 9.b. Out-of-sample MSE for the Constant Long Term Component Volatility and the GARCH-MIDAS Volatility with Selected Indicators. CCC rated bonds.

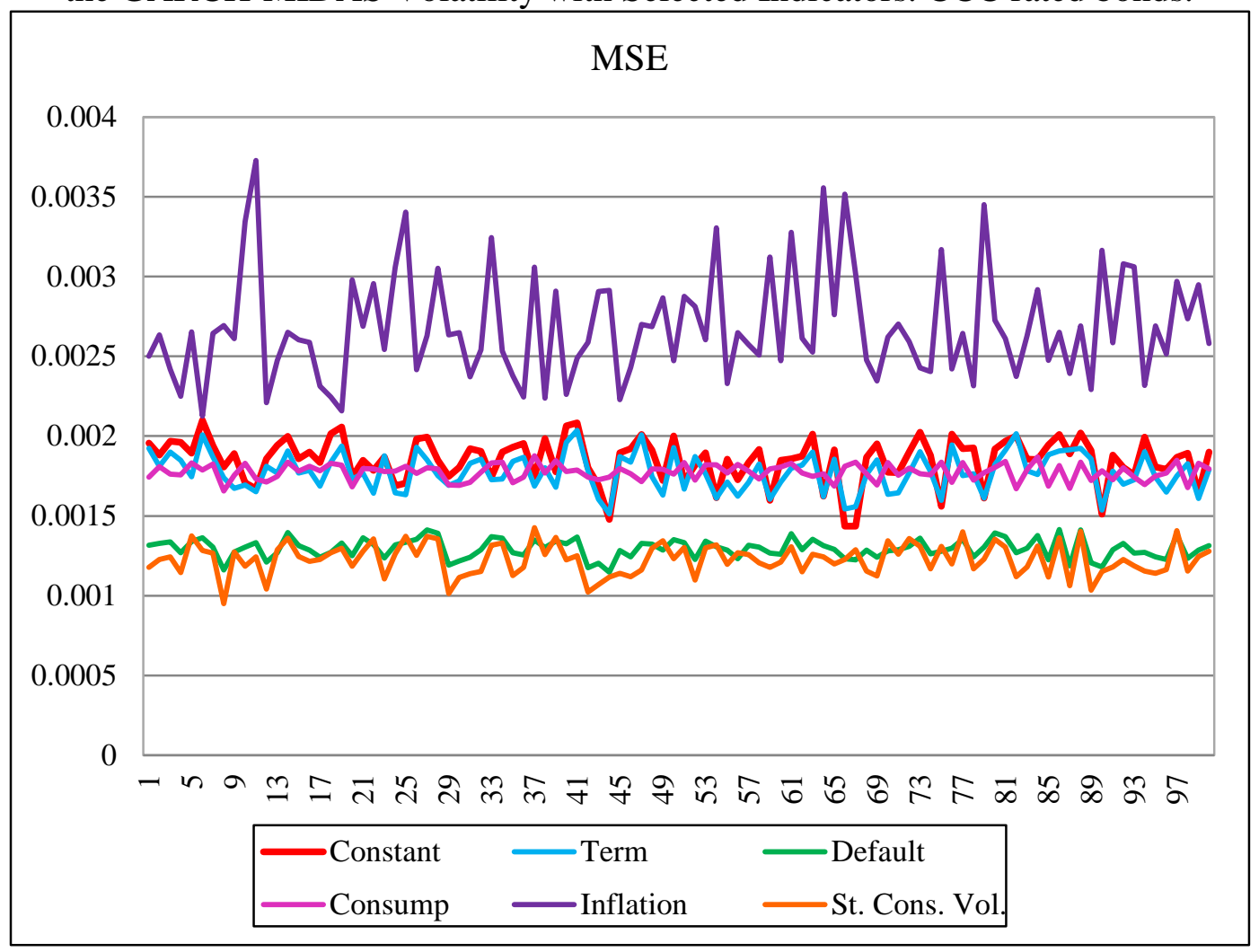

